\title{
Numerical Study of the Effect of Perforation Friction and Engineering Parameters on Multicluster Fracturing in Horizontal Wells
}

\author{
Zixi Jiao, ${ }^{1}$ Anlin Zhang, ${ }^{2}$ Longhuan Du $\mathbb{D},{ }^{3}$ Yang Yang, ${ }^{1}$ and Hua Fan ${ }^{4}$ \\ ${ }^{1}$ Key Laboratory of Deep Underground Science and Engineering, Sichuan University, Ministry of Education, Chengdu 610065, China \\ ${ }^{2}$ College of Water Resource and Hydropower, Sichuan University, Chengdu 610065, China \\ ${ }^{3}$ College of Architecture and Environment, Sichuan University, Chengdu 610065, China \\ ${ }^{4}$ Lingchuang Green House Construction Technology Co., Ltd., Chengdu 610065, China
}

Correspondence should be addressed to Longhuan Du; longhuan_du@163.com

Received 8 July 2021; Revised 16 August 2021; Accepted 18 August 2021; Published 1 September 2021

Academic Editor: Steffen Berg

Copyright (c) 2021 Zixi Jiao et al. This is an open access article distributed under the Creative Commons Attribution License, which permits unrestricted use, distribution, and reproduction in any medium, provided the original work is properly cited.

Simultaneous multiple-fracture treatments in horizontal wellbores have become one of the key methods for economically and efficiently developing oil and gas resources in unconventional reservoirs. However, field data show that some perforation clusters have difficulty propagating fractures due to the internal mechanism of competing initiation and propagation among the fractures. In this paper, the physical mechanisms that influence simultaneous multiple-fracture initiation and propagation are investigated, and the effects of engineering parameters and in situ conditions on the nonuniform development of multiple fractures are discussed. A 3D fracture propagation model was established with ABAQUS to show the influence of the stress shadow effects and dynamic partitioning of the flow rate by simulating the propagation of multiple competing fractures generated in the perforation clusters. Based on the results of these simulations, simultaneous flow in multiple fractures can propagate evenly. Through adjusting the number of perforations in each cluster or the perforation diameter, the effect of the stress shadow can be significantly reduced by increasing the perforation friction, and the factors that affect the development of multiple fractures are changed, from the stress shadow effect to the dynamic partitioning of the flow rate. When the stress shadow effect is dominant, increasing the fracturing fluid viscosity promotes the uniform development of multiple fractures and increases the fracture width. When the dynamic partitioning of the flow rate is dominant, increasing the injection rate greatly affects the uniform development of multiple fractures.

\section{Introduction}

The hydraulic fracturing technique is a widely used wellstimulation technique to effectively and economically develop oil and gas resources in low-permeability unconventional reservoirs [1,2]. Many field measurements, laboratory tests, and reservoir simulation studies [3-7] have proven that multicluster hydraulic fracturing and horizontal drilling are the key hydraulic fracturing methods. The advantage of multicluster fracturing over conventional hydraulic fracturing is that it allows multiple perforation clusters within a single stage to form several hydraulic fractures simultaneously through a single pump, resulting in multiple fracture surfaces after fracturing fluid is pumped into the reservoir, thus achieving a larger effective reservoir volume. Bunger [4] believed that when the spacing of perforations was greater than $1.5 \mathrm{~h}$, it was conducive to the uniform development of multiple fractures formed by multicluster fracturing. However, too large of a spacing of perforation clusters made it difficult to form a large effective reservoir volume and improve the ultimate reservoir recovery [8]. At the same time, engineering-analysis results indicated that when perforation cluster spacing was set too closely, multiple fractures had difficulty propagating evenly after initiation 
simultaneously. Miller et al. [9] applied the surface tiltmeter fracture mapping method to quantify the fracture volume growth along several horizontal wells and found that the midlateral volume could not achieve the expected value of the perforation cluster design. Spain et al. [10] concluded that close cluster spacing is beneficial for well production, but if the spacing is too close, excessive induced stress causes fracture competition, resulting in the nonuniform development problems of difficult growth of fractures in the midlateral and excessive growth of fractures at both ends. To obtain a reasonable multiple-fracture treatment design and acceptable well production, a deep understanding of the competitive propagation mechanism of fractures during fracturing is urgently needed.

In recent years, increasing attention has been given to the mechanism of simultaneous propagation in multiple fractures in unconventional reservoirs. When multiple fractures propagate simultaneously, individual fracture can be created within each cluster, which is favourable to expand the stimulated reservoir volume. Some laboratory tests have been designed to simulate this process [11, 12]. El Rabaa [11] studied the effect of perforation cluster spacing on hydraulic fracturing through laboratory tests and found that when the main fracture appeared, the remaining fractures were difficult to develop completely. Zhu et al. [12] conducted hydraulic fracturing tests on concrete samples with oriented perforations and found that all fractures initiated from the perforation holes, but not all fractures were fully developed. Compared to tests, numerical simulation methods can better represent the reservoir in situ conditions and the nonlinear dynamic boundary problem, which is influenced by many factors, such as the Young modulus of the target layer, fracturing fluid viscosity, and pump rate [13]. Therefore, the numerical simulation method is suitable for simultaneous multiple-fracture propagation in horizontal wellbores in unconventional reservoirs. For example, based on the displacement discontinuity method, Olson [14] found that when the fracture spacing is small, even if the fluid is evenly distributed between the perforation clusters, middle fractures cannot develop. Cheng [15] demonstrated that when the cluster spacing is reduced to an inadequately small size, production is reduced, and fracture width is limited. With the help of the finite element method, Salimzadeh et al. [16] showed that the interaction between adjacent fractures leads to growth away from each other, which is weakened when the fracture spacing is large. Shin and Sharma [17] built a 3D geomechanical model to explore how various factors control the simultaneous propagation of multiple competing fractures in horizontal wells. Haddad and Sepehrnoori [18] simulated the arbitrary, solutiondependent initiation and propagation path of multiple fractures caused by multicluster hydraulic fracturing and found that different cluster spacings would lead to coalescing, growing parallel, or diverging multiple fractures. From the perspective of the continuum method, Zhao et al. [19] investigated when the spacing between perforations is reduced to a certain extent, the fracturing regions formed by the perforations coalesces after a period of development, and multiple perforations can be considered as a single perforation with a larger injection rate. In previous studies, scholars found that perforation-cluster spacing, fracture height, target formation thickness, and pumping rate had significant influence on the simultaneous propagation of multiple fractures in a horizontal well [17].

There are two mechanisms of fracture mechanical interaction during the simultaneous propagation of multiple fractures. One is the stress shadow effect, and the other is the dynamic partitioning of the flow rate [20, 21]. Existing models [22-24] have explored the effect of each mechanism on the geometry of multiple fractures. For example, Guo et al. [22] established a 3D seepage-stress-damage coupled multifracture simultaneous propagation model to explore the stress field of multiple fractures with different cluster spaces. Yang et al. [23] built a pseudo-3D model based on the displacement discontinuity method (DDM) and found that perforation friction has an important effect on the dynamic partitioning of the flow rate. The influence of the stress shadow occurs when multiple competing fractures in horizontal wells propagate simultaneously. When fracturing fluid is pumped into multiple fractures, compressive stress that acts on adjacent fracture surfaces can increase the difficulty of multiple fracture propagation and even lead to the closure of the fractures. From the numerical simulation analysis, through a reasonable design, such as the reasonable perforation cluster spacing, the injection rate, and the fracturing fluid viscosity, the adverse effects of the stress shadow can be controlled. Then, the difficult propagation of the fractures along the midlateral and the overdevelopment of fractures at the heel and toe of wellbores can be avoided to a certain extent [25-27]. In addition, the in situ characteristics of the target reservoir, such as in situ stress, Young's modulus, and thickness, can also affect the results of multicluster fracturing with the same design parameters [28-30]. In most numerical studies, the fluid flow rate in each perforation was assumed to be constant, and only the influence of the stress shadow could be considered. However, due to the existence of friction, the flow rate allocated to each fracture affects the geometry of the fractures. Some researchers [3133] have established a numerical model that can dynamically determine the split of the flow rate in the process of multicluster fracturing. The results showed that the dynamic partitioning of the flow rate has an important influence on the uniform propagation of multiple competing fractures. In actual engineering, to ensure production, it is often necessary to set a small cluster spacing, but the small cluster spacing causes strong stress interference between fractures; thus, it is difficult for some perforation clusters to play a role in stimulation. Therefore, it is necessary to design engineering parameters such as the fracturing fluid viscosity, injection rate, number of perforations in each perforation cluster, and perforation diameter to make multiple fractures propagate evenly. Different fracture designs have different mechanisms that govern the development of multiple fractures. However, few previous studies have comprehensively considered how to combine the effects of different operating parameters on fracture development with the dominant fracture mechanical interaction mechanism to improve the effectiveness of multicluster fracturing. 
In this paper, ABAQUS software is used to build a novel 3D multicluster fracturing model that simulates the simultaneous propagation of multiple competing fractures and to investigate the effects of commonly used operating parameters on the uniform propagation of multiple fractures. Importantly, the dynamic partitioning of the flow rate due to the different fluid flow resistances and the stress interaction between the fractures due to the complex in situ conditions is considered in the model. The geometry of each fracture and the fluid flow into each fracture to promote the propagation of multiple fractures are obtained. The influence of fracturing fluid viscosity, injection rate, and perforation friction on the uniform development of multiple fractures is analysed comprehensively by using this model, and some suggestions to promote uniform multiplefracture growth are proposed.

\section{Physical Model}

After the horizontal well is segmented, multicluster fracturing technology is used. Multicluster fracturing allows multiple perforation clusters in an injection stage of a horizontal well, and then, a fracture is generated in each cluster, increasing the stimulated reservoir volume (SRV) in a single stage after the fracturing fluid is pumped. The simplified physical model of multicluster fracturing within a stage is shown in Figure 1. As it is a complex process for multiple fracture propagation, the following assumptions are introduced:

(1) The reservoir rock is regarded as an isotropic, poroelastic material

(2) Each perforation cluster within a stage generates only a main fracture

(3) Bunger [29] found that when the horizontal stress difference reached 2-3 MPa, the fracture plane bending phenomenon caused by stress shadow effects between adjacent fractures could be effectively suppressed. The fractures are assumed to be planar and vertical

(4) The fracturing fluid is considered an incompressible Newtonian fluid, and the flow pattern of the fluid in the fractures is consistent with Poiseuille plate flow. In addition, the connection between the pipeline and the formation injection point is filled with fluid

Finally, based on the physical model, the geometry of multiple fractures affected by in situ stress conditions, the operation parameters, and the interaction between multiple competing fractures are discussed.

\section{Model Geometry}

The geometry of the model established in this paper is shown in Figure 2. The model is used to simulate the initiation and propagation of multiple competing fractures within a stage due to multicluster fracturing and consists of reservoirs, upper and lower barriers, a horizontal wellbore, and perforation

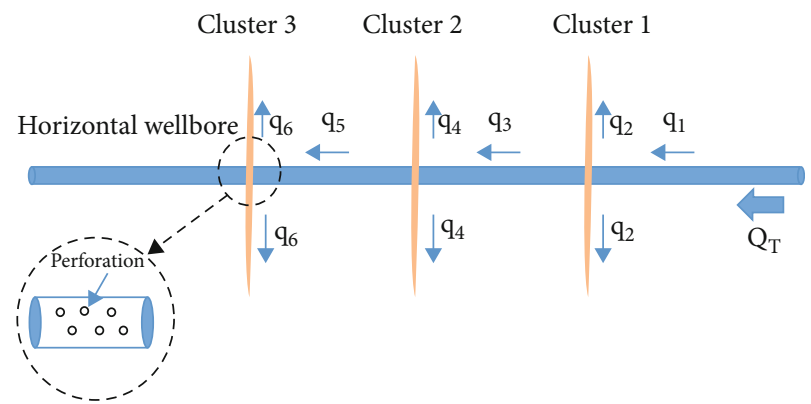

Figure 1: Schematic of multicluster fracturing within a stage.

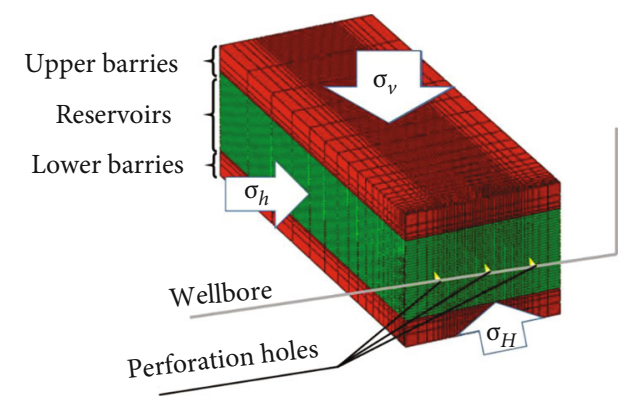

Figure 2: Schematic of fracture propagation model.

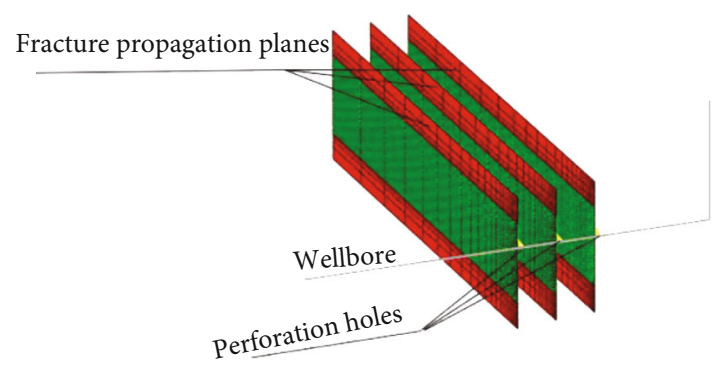

Figure 3: A plane of COH3D8P elements was embedded in the C3D8P elements at each perforation cluster to simulate fractures.

holes. Since the initiation and propagation of hydraulic fractures are symmetric on both sides of the wellbore, only one side of the wellbore is taken for modelling. C3D8P elements (8-node brick, trilinear displacement, and trilinear pore pressure) were used to model the reservoir as a porous elastic medium. The cohesive elements (COH3D8P) are embedded at each perforation cluster along the horizontal wellbore to determine the path of the hydraulic fractures to initiate and propagate in a direction perpendicular to the minimum horizontal principal stress, as shown in Figure 3. The FPC3D2 connector element is used to hydraulically connect the perforated clusters to force pressure continuity between the clusters, and pipe flow elements FP3D2 are used in the wellbore to describe the pressure drop due to frictional resistance in the wellbore. Fluid can enter the reservoir only through perforation clusters. The height of the hydraulic fractures is limited by the upper and lower barriers.

\section{Mathematical Model}

\subsection{Fluid Flow Model}


4.1.1. Fluid Flow in Fracture and Reservoir. The flow of fluid within the cohesive elements consists of tangential flow rate and normal flow rate. The tangential flow rate represents fluid flow through the fractures, while the normal flow rate represents the fluid loss to the formation. The tangential flow of fluid within fractures was modelled using Reynold's equation $[34,35]$.

$$
q=-\frac{w^{3}}{12 \mu} \nabla p
$$

where $q$ is the tangential flow rate, $\mathrm{m}^{3} / \mathrm{s} ; \nabla p$ is the pressure gradient along the fracture, $\mathrm{MPa} / \mathrm{m} ; w$ is the fracture aperture, $\mathrm{m}$; and $\mu$ is the fracture viscosity, $\mathrm{cp}$.

The normal flow represents fluid leak-off from the fracture to the formation and can be expressed by setting the fluid leak-off coefficient in the following equation:

$$
\left\{\begin{array}{l}
q_{\mathrm{t}}=c_{\mathrm{t}}\left(p_{\mathrm{f}}-p_{\mathrm{t}}\right), \\
q_{\mathrm{b}}=c_{\mathrm{b}}\left(p_{\mathrm{f}}-p_{\mathrm{b}}\right),
\end{array}\right.
$$

where $q_{\mathrm{t}}$ and $q_{\mathrm{b}}$ are the flow rates into the top and bottom surfaces, $\mathrm{m}^{3} / \mathrm{s}$, respectively; $c_{\mathrm{t}}$ and $c_{\mathrm{b}}$ are the leak-off coefficients of the top and bottom surfaces, respectively; $p_{\mathrm{f}}$ is the midface pressure, $\mathrm{Pa}$; and $p_{\mathrm{t}}$ and $p_{\mathrm{b}}$ are the pore pressures on the top and bottom surfaces, respectively.

4.1.2. Fluid Distribution between Perforation Clusters. Multicluster fracturing within a stage produces multiple competing fractures. When multiple fractures initiate and propagate simultaneously, the fracturing fluid enters each fracture. The dynamic partitioning of the flow rate of each fracture needs to be considered in the model according to the corresponding boundary conditions. When the wellbore storage effect is ignored, it is assumed that the fluid pressure at the inlet of each cluster is equal. In addition, the total injection rate is equal to the sum of the inflow rate of all clusters.

$$
Q_{\mathrm{to}}=\sum_{i=1}^{N} Q_{i},
$$

where $Q_{\text {to }}$ is the sum of all fracture flow rates, $\mathrm{m}^{3} / \mathrm{s} ; Q_{i}$ is the flow rate of fracturing fluid distributed in fracture $I$, $\mathrm{m}^{3} / \mathrm{s}$; and $N$ is the number of perforations in each perforation cluster.

By analysing the data from the field experiments and laboratory tests, when the fracturing fluid pumped from the wellbore through the perforation entry to the hydraulic fracture tip, the total pressure dropped, which was due to wellbore friction and perforation-entry friction [36]. Finally, the treating pressure inside the fractures was different from the treating pressure inside the casing. Considering the influence of wellbore friction and perforation-entry friction on fluid flow, according to Kirchhoff's second law [36], the bottomhole treating pressure $p_{\mathrm{w}}$ is equal to the sum of the pressure $p_{\text {in }}$ at the mouth of the fracture, pressure $p_{\mathrm{b}}$ caused by fluid friction in the wellbore, and pressure $p_{\mathrm{f}}$ caused by fracture-entry friction.

$$
p_{\mathrm{w}}=p_{\text {in }}+p_{\mathrm{b}}+p_{\mathrm{f}}
$$

where $p_{\mathrm{w}}$ is the bottomhole treating pressure, $\mathrm{MPa} ; p_{\text {in }}$ is the pressure at the mouth of the fracture, $\mathrm{MPa} ; p_{\mathrm{b}}$ is the pressure caused by fluid friction in the wellbore, $\mathrm{MPa}$; and $p_{\mathrm{f}}$ is the pressure caused by fracture-entry friction, MPa.

By using a pipe flow element (FP3D2) in the wellbore, the wellbore frictional pressure drop can be calculated using the Churchill method:

$$
\begin{aligned}
\Delta P-\rho g \Delta Z & =\left(C_{\mathrm{L}}+K_{i}\right) \frac{\rho v^{2}}{2}, \\
C_{\mathrm{L}} & =\frac{f L}{D_{\mathrm{h}}}, \\
f & =8\left[\left(\frac{8}{R e}\right)^{12}+\frac{1}{(A+B)^{1.5}}\right]^{1 / 12} \\
A & =\left[-2.457 \ln \left(\left(\frac{7}{R e}\right)^{0.9}+0.27\left(\frac{K_{\mathrm{s}}}{D_{\mathrm{h}}}\right)\right)\right]^{16}, \\
B & =\left(\frac{37350}{\operatorname{Re}}\right)^{16},
\end{aligned}
$$

where $\Delta P$ is the pressure difference at the nodes, $\mathrm{MPa} ; \Delta \mathrm{Z}$ is the elevation difference at the nodes, $\mathrm{m} ; v$ is the fluid velocity in the pipe, $\mathrm{m} / \mathrm{s} ; \rho$ is the fluid density, $\mathrm{kg} / \mathrm{m}^{3} ; g$ is the acceleration due to gravity; $C_{\mathrm{L}}$ is the loss coefficient; $f$ is the friction of the pipe; $L$ is the length of the pipe, $\mathrm{m} ; K_{i}$ is a directional loss term; $K_{\mathrm{s}}$ is the roughness of the pipe; and $D_{\mathrm{h}}$ is the hydraulic diameter.

By using the connector element (FPC3D2), the perforation frictional pressure drop can be calculated according to the formula of Crump [32, 36].

$$
p_{\mathrm{f}}=0.807249 \times \frac{\rho}{n^{2} D_{\mathrm{P}}^{4} C^{2}} Q_{i}^{2}
$$

where $n$ is the number of perforations in each perforation cluster; $D_{\mathrm{p}}$ is the diameter of perforation, $\mathrm{m}$; and $C$ reflects the influence of perforation shape on perforation friction. When the perforation is intact, the value is generally $0.5 \sim 0.6$, and when the perforation is completely eroded, the value is generally 0.95 [37].

4.2. CZM Model. Linear elastic fracture mechanics (LEFM) is one of the common criteria for fracture initiation and propagation. According to LEFM theory, when the stress intensity factor of the rock is greater than the fracture toughness, the fracture initiates and propagates. However, considering only the stress intensity factor makes it difficult to fully characterize the fracture propagation because LEFM does not consider the inelastic region near the crack tip. 
The cohesive zone method (CZM) is another method to describe the fracture process zone. When modelling the fracture, the fracture is divided into two parts: one is the real fracture length, and the other is a cohesive zone. Based on the traction-separation criterion, the initiation and propagation behaviours of fractures are simulated. In the early stage, the fracture is subjected to an external load, and the stress increases linearly with the opening/shearing displacement before reaching the threshold value. Once the stress reaches the threshold value, the stress gradually decreases, and at this time, the interface begins to suffer damage.

The quadratic traction-interaction failure criterion [38] is used to simulate fracture initiation and propagation, and the effect of normal stress and tangential stress is considered. A typical cohesive traction-interaction failure criterion is shown in Figure 4. When the crack is initiated, the quadratic interaction function value is 1 , and its expression is as follows:

$$
\left\{\frac{\left\langle t_{\mathrm{n}}\right\rangle}{t_{\mathrm{n}}^{0}}\right\}^{2}+\left\{\frac{t_{\mathrm{s}}}{t_{\mathrm{s}}^{0}}\right\}^{2}+\left\{\frac{t_{\mathrm{t}}}{t_{\mathrm{t}}^{0}}\right\}^{2}=1
$$

where $t_{\mathrm{n}}, t_{\mathrm{s}}$, and $t_{\mathrm{t}}$ represent the normal, first, and second shear stress components, Pa, respectively; $t_{\mathrm{n}}^{0}, t_{\mathrm{s}}^{0}$, and $t_{\mathrm{t}}^{0}$ represent the peak values of the nominal stress when the deformation is either purely normal to the interface or purely in the first or second shear direction, $\mathrm{Pa}$, respectively; and the symbol $<>$ is the Macaulay bracket used to indicate that a pure compression deformation or stress state does not initiate damage.

After fracture initiation, the damage was evaluated by fracture energy theory. The Benzeggagh and Kenane [39] fracture criterion was introduced to describe the development of fractures after fracture initiation, and the criterion is useful when the critical fracture energies along different tangential directions are the same.

$$
G_{\mathrm{n}}^{\mathrm{C}}+\left(\mathrm{G}_{\mathrm{s}}^{\mathrm{C}}-\mathrm{G}_{\mathrm{n}}^{\mathrm{C}}\right)\left\{\frac{G_{\mathrm{s}}+G_{\mathrm{t}}}{G_{\mathrm{n}}+G_{\mathrm{s}}+G_{\mathrm{t}}}\right\}^{\eta}=G^{\mathrm{C}}
$$

where $G_{\mathrm{n}}^{\mathrm{C}}$ represents the critical fracture energy in model I; $G_{s}^{\mathrm{C}}$ represents the critical fracture energy in model II; $G_{\mathrm{n}}$ $G_{\mathrm{s}}$, and $G_{\mathrm{t}}$ represent the fracture energy of the normal direction, the first tangential direction, and the second tangential direction, respectively; $\eta$ is the material parameter.

If the fracture energy reaches or exceeds $G_{\mathrm{C}}$ $\left(G_{\mathrm{C}}=G_{\mathrm{n}}+G_{\mathrm{s}}+G_{\mathrm{t}}\right)$, the cohesive element breaks, and the fracture begins to propagate.

\section{Model Building}

In the numerical model, the reservoir is assumed to be homogeneous, and the fracture expands symmetrically on both sides of the wellbore. Therefore, only half of the fractures are established to study the initiation and propagation of multiple fractures. The height of the reservoir model is $30 \mathrm{~m}$, the length is $160 \mathrm{~m}$, and the width is $60 \mathrm{~m}$. The height of the upper and lower layers is set to $10 \mathrm{~m}$, which forces

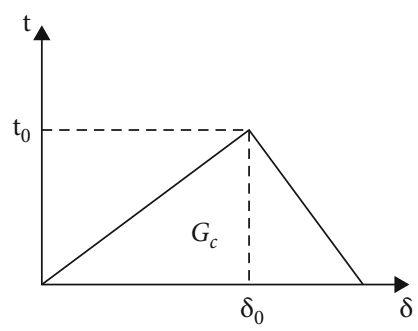

FIGURE 4: Cohesive traction-interaction failure criterion.

fracture propagation to be confined to the target formation. In this model, three perforating clusters are set in a stage, and the cluster spacing is $15 \mathrm{~m}$. 21].

The target formation properties are presented below [3,

The parameters of the upper and lower layers are the same, as follows.

Equation (6) shows that perforation friction changes as the number of perforations or the diameter of perforations changes. When the perforation friction is small, the development of multiple fractures is dominated by the stress shadow effect, intermediate fractures have difficulty developing completely, and the development stops before pumping for $50 \mathrm{~s}$. With the increase in perforating friction, the development of multiple fractures is dominated by the dynamic partitioning of the flow rate, and the three fractures continue to propagate after pumping for $50 \mathrm{~s}$. Different perforation parameters in the fracturing process lead to different pressure drops of perforation clusters and affect the initiation and propagation process of multiple perforation clusters. The hydraulic fracturing design parameters of each working condition are presented below.

\section{Results and Discussion}

In this section, we discuss the simultaneous propagation of multiple fractures formed by multicluster fracturing and the corresponding influencing factors based on the numerical model established in Section 5. For this study, the basic parameters of the reservoir and the upper and lower layers are obtained from Tables 1 and 2, and the engineering parameters used in various working conditions are shown in Table 3.

In the following discussion, fractures 1,2 , and 3 represent the fractures that initiate from the left, middle, and right clusters, respectively, in Figure 3.

6.1. The Basic Case (Case 1). In this model, each cluster has 32 perforations, and the perforation diameter is $15 \mathrm{~mm}$. The total injection rate is $6 \mathrm{~m}^{3} / \mathrm{min}$, and the fracturing fluid viscosity is $1 \mathrm{cp}$. Note that the effect of perforation friction on fracture initiation and propagation is negligible. In this case, the simultaneous initiation and propagation of multiple fractures are mainly affected by stress interference between fractures. The morphologies of three hydraulic fractures after $5 \mathrm{~s}, 20 \mathrm{~s}, 30 \mathrm{~s}$, and $50 \mathrm{~s}$ of pumping are shown in Figure 5. The colour in the figure represents the width of 
TABLE 1: Basic parameters of the target formation.

\begin{tabular}{lc}
\hline Minimum horizontal stress $(\mathrm{MPa})$ & 30.68 \\
\hline Maximum horizontal stress $(\mathrm{MPa})$ & 37.58 \\
Vertical stress $(\mathrm{MPa})$ & 55 \\
Young's modulus $(\mathrm{GPa})$ & 45 \\
Poisson's ratio & 0.2 \\
Reservoir layer thickness $(\mathrm{m})$ & 30 \\
\hline
\end{tabular}

TABLE 2: Basic parameters of the upper and lower layers.

\begin{tabular}{lc}
\hline Minimum horizontal stress $(\mathrm{MPa})$ & 35.68 \\
\hline Maximum horizontal stress $(\mathrm{MPa})$ & 39.58 \\
Vertical stress $(\mathrm{MPa})$ & 55 \\
Young's modulus $(\mathrm{GPa})$ & 90 \\
Poisson's ratio & 0.3 \\
Reservoir layer thickness $(\mathrm{m})$ & 10 \\
\hline
\end{tabular}

the propagated fracture. The exact value of each colour corresponds to the different opening widths of the fracture in the right panel of the image in meters. The blue areas in the figure represent the fracture propagation planes where the fracture has not yet developed. Other areas represent the fractures. All three fractures started to propagate at the same time when the fracturing fluid was pumped when $t=$ $5 \mathrm{~s}$ (see Figure 5). However, as Figure 5 shows, after some time, with the opening of the fractures on both sides, an increased additional compressive stress applied to the middle fracture tends to inhibit the propagation of the middle fracture. Previous studies have proven that when the cluster spacing is small, fractures in the middle position have difficulty propagating due to the inability to allocate enough fracturing fluid, and perforation clusters in the middle position become ineffective. Increasing cluster spacing can weaken the influence of the stress shadow effect, but tight cutting and reasonable distribution of well spacing in horizontal well staging are also the keys to reservoir reconstruction. Therefore, it is an effective way to optimize the multicluster fracturing design within a stage in a horizontal well by adjusting the engineering parameters and setting reasonable perforation parameters to form a sufficient pressure drop so that multiple fractures can form a large effective fracture volume at an appropriate cluster spacing.

6.2. The Effect of the Injection Rate when the Value of Perforation Friction Is Small (Cases 1 and 2). The injection rate is an important engineering parameter. Based on the reference model in case 1, different flow rates are considered: $6 \mathrm{~m}^{3} / \mathrm{min}$ and $10 \mathrm{~m}^{3} / \mathrm{min}$. Then, the effect of the flow rate on the growth of multiple fractures is studied. The fracture geometry injected with fluid in case 1 is shown in Figure 5, and that injected with fluid in case 2 is shown in Figure 6.

The change curve image of the maximum fracture width along the direction of fracture propagation is shown in Figure 7. Figures 7(a) and 7(b) show that the development of the three fractures has the same trend in the two cases. The width of the fractures increases rapidly with the initia- tion of the fractures, and then, the width of the middle fracture decreases continuously due to the compressive stress exerted by the propagation of the fractures on both sides until it approaches $0 \mathrm{~mm}$. The fractures on both sides continued to fluctuate, and after a certain period, the widths of the three fractures remained stable with the injection of fluid. Figure $7(a)$ shows that the maximum fracture widths of fractures 1, 2, and 3 are $1.2 \mathrm{~mm}, 0.895 \mathrm{~mm}$, and $1.23 \mathrm{~mm}$, respectively. The maximum width of fracture 2 is almost zero after $17 \mathrm{~s}$. It can be seen from Figure 7(b) that the maximum fracture widths of fractures 1,2 , and 3 are $1.406 \mathrm{~mm}, 0.946 \mathrm{~mm}$, and $1.453 \mathrm{~mm}$, respectively. The maximum width of fracture 2 is almost zero after $14 \mathrm{~s}$. As shown in Figure 6, as the injection rate increases, the lateral fractures propagate for a longer area after pumping the $50 \mathrm{~s}$ fracture fluid, and the width of the middle fracture lasts for a shorter period. This means that when the stress shadow effect dominates, higher pump rates cause fluid to enter the middle fracture more difficult and to enter the lateral fracture more quickly, creating more significant compressive stress and resulting in the faster closure of the middle fracture.

The dynamic percentage of the flow rate into each cluster is illustrated in Figure 8. In Figure 8(a), the percentage of flow into fracture 2 is almost 0 after $14 \mathrm{~s}$. The percentage of flow into fracture 1 and fracture 3 is almost identical. The percentage of flow into fracture 1 and fracture 3 is almost the same at first, but as more fracturing fluid is pumped, the flow percentage into fracture 1 is gradually higher than that entering fracture 3 , and this trend slowly increases. Figure 8 (b) shows that the percentage of flow into fracture 2 is almost zero after 11 s. Combined with Figures 6 and 7, it can be seen that the larger flow volume ratio is the reason why fractures on both sides can propagate a longer area. When fracturing fluid enters the three fractures from the three injection points, the fracturing fluid splits along multiple paths. However, due to the strong stress shadow effect and high injection rate after initiating on both sides of the fracture, the fracturing fluid experiences continuous propagation, and the middle fracture closes after a short time. Fracture 3 at the front of the wellbore contains a larger proportion of fracturing fluid than fracture 1 at the back of the wellbore due to wellbore friction.

After pumping for $20 \mathrm{~s}$ and $50 \mathrm{~s}$, the percentage of flow into each cluster is presented in Figure 9. This information is useful for studying the dynamic partitioning of the fluid rate across fractures after fracturing fluid is pumped. The percentage of flow into fracture 2 is the minimum and is much smaller than the percentage of flow into the fractures on either side. The percentage of flow into fracture 3 is more than the percentage of flow into fracture 1 because of the effect of wellbore fluid friction. When the total injection rate ranges from $6 \mathrm{~m}^{3} / \mathrm{min}$ to $10 \mathrm{~m}^{3} / \mathrm{min}$, due to the stress shadow effect, fracture 2 still cannot be fully developed, and the flow rate uniformity into both sides of the fracture worsens as the fracturing fluid is pumped, ranging from modest $1.02 \%$ and $0.27 \%$ at $20 \mathrm{~s}$ to $5.63 \%$ and $8.198 \%$ at $50 \mathrm{~s}$, respectively. Therefore, it is believed that increasing the flow rate is not conducive to the uniform development 
TABLE 3: Hydraulic fracturing design parameters in different cases.

\begin{tabular}{|c|c|c|c|c|c|}
\hline Case & $\begin{array}{l}\text { Value of the perforation } \\
\text { friction }\end{array}$ & $\begin{array}{c}\text { Number of perforations of each } \\
\text { cluster }\end{array}$ & $\begin{array}{l}\text { Perforation diameter } \\
\qquad(\mathrm{mm})\end{array}$ & $\begin{array}{c}\text { Total injection rate }\left(\mathrm{m}^{3} /\right. \\
\text { min) }\end{array}$ & $\begin{array}{l}\text { Viscosity } \\
\text { (cp) }\end{array}$ \\
\hline $\begin{array}{l}\text { Case } \\
1\end{array}$ & Small & 32 & 15 & 6 & 1 \\
\hline $\begin{array}{l}\text { Case } \\
2\end{array}$ & Small & 32 & 15 & 10 & 1 \\
\hline $\begin{array}{l}\text { Case } \\
3\end{array}$ & Small & 32 & 15 & 6 & 100 \\
\hline $\begin{array}{l}\text { Case } \\
4\end{array}$ & Small & 8 & 15 & 6 & 1 \\
\hline $\begin{array}{l}\text { Case } \\
5\end{array}$ & Large & 32 & 5 & 6 & 1 \\
\hline $\begin{array}{l}\text { Case } \\
6\end{array}$ & Large & 32 & 5 & 8 & 1 \\
\hline $\begin{array}{l}\text { Case } \\
7\end{array}$ & Large & 32 & 5 & 10 & 1 \\
\hline $\begin{array}{l}\text { Case } \\
8\end{array}$ & Large & 32 & 5 & 6 & 10 \\
\hline $\begin{array}{l}\text { Case } \\
9\end{array}$ & Large & 32 & 5 & 6 & 100 \\
\hline
\end{tabular}

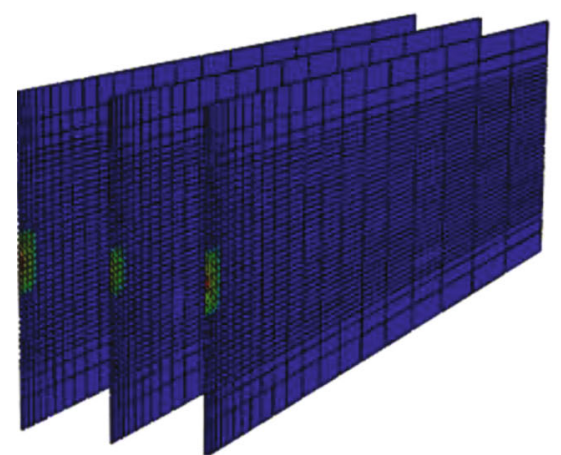

$5 s$

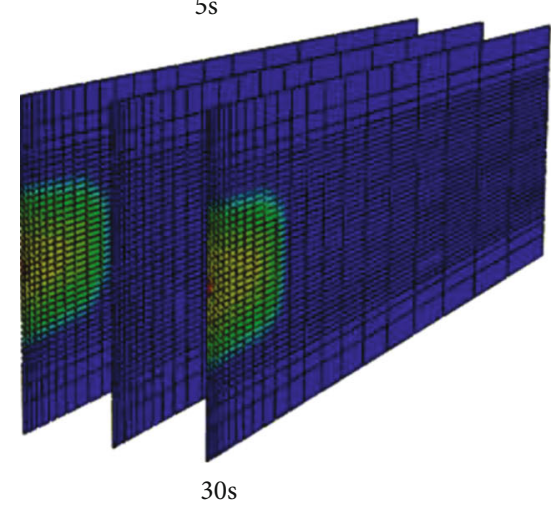

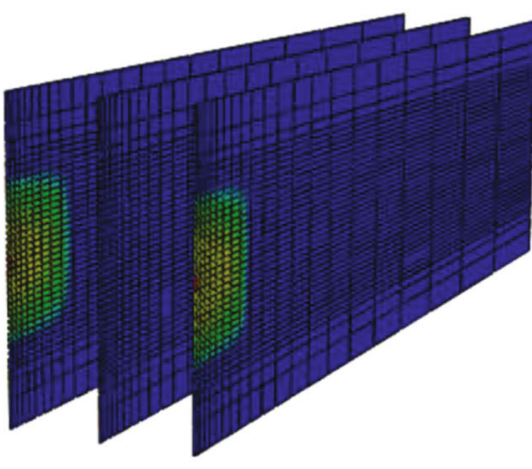

PEN

(平纤: 75\%)

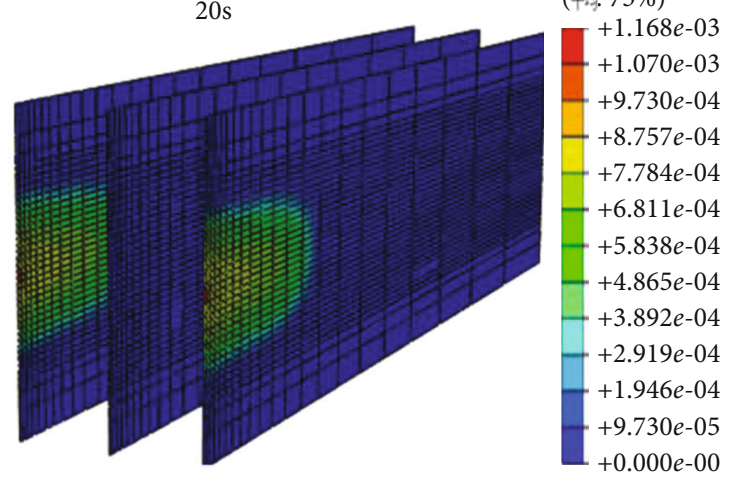

50 s

Figure 5: Fracture geometry after pumping for $5 \mathrm{~s}, 20 \mathrm{~s}, 30 \mathrm{~s}$, and $50 \mathrm{~s}$ in case 1 .

of fractures when perforation friction is not considered and that the influence of the stress shadow effect is the main factor.

In engineering, when the perforation friction is small, increasing the injection rate is favourable to the development of the fractures on both sides. However, the utilization effect of the middle perforating cluster will be significantly reduced, which is not conducive to the uniform development of multiple fractures.

6.3. The Effect of Fracturing Fluid Viscosity when the Value of Perforation Friction Is Small (Case 1 and Case 3). Fracturing fluid viscosity is an important engineering parameter. Based on the reference model in case 1, different fracturing fluid 

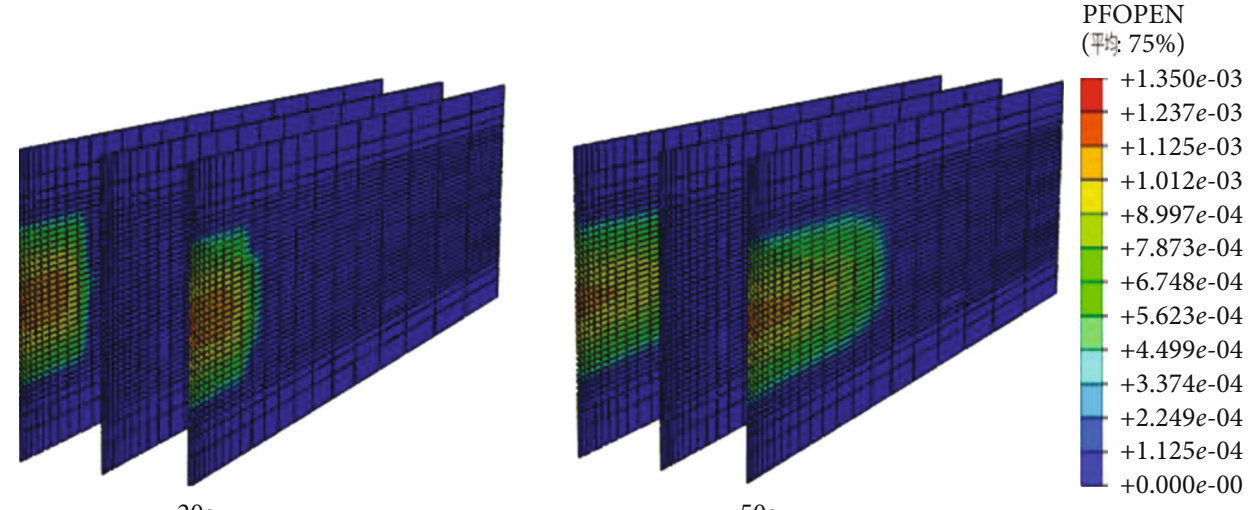

20 s

$50 \mathrm{~s}$

FIgURE 6: Fracture geometry after pumping for $20 \mathrm{~s}$ and $50 \mathrm{~s}$ in case 2.

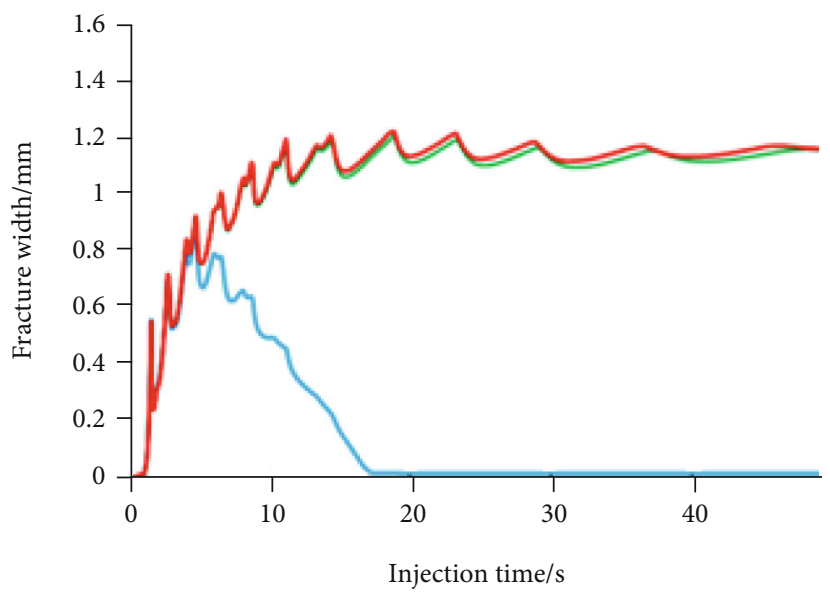

(a)

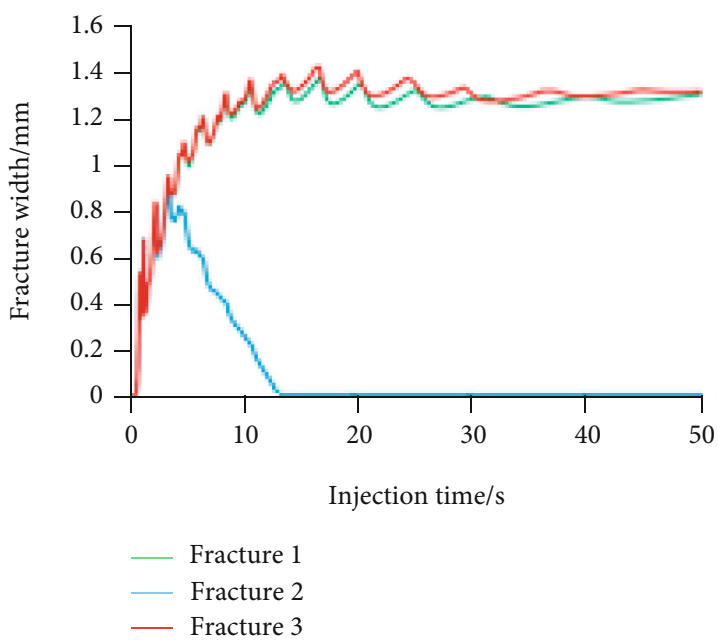

(b)

FIGURE 7: The maximum fracture width of each cluster as a function of time for different flow rates: (a) case $1\left(6 \mathrm{~m}^{3} / \mathrm{min}\right)$; (b) case 2 $\left(10 \mathrm{~m}^{3} / \mathrm{min}\right)$.

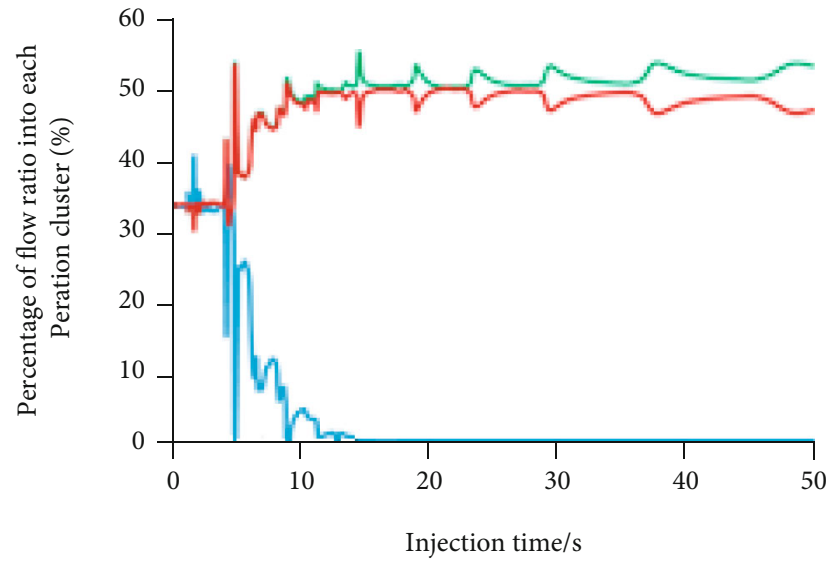

Injection time/s

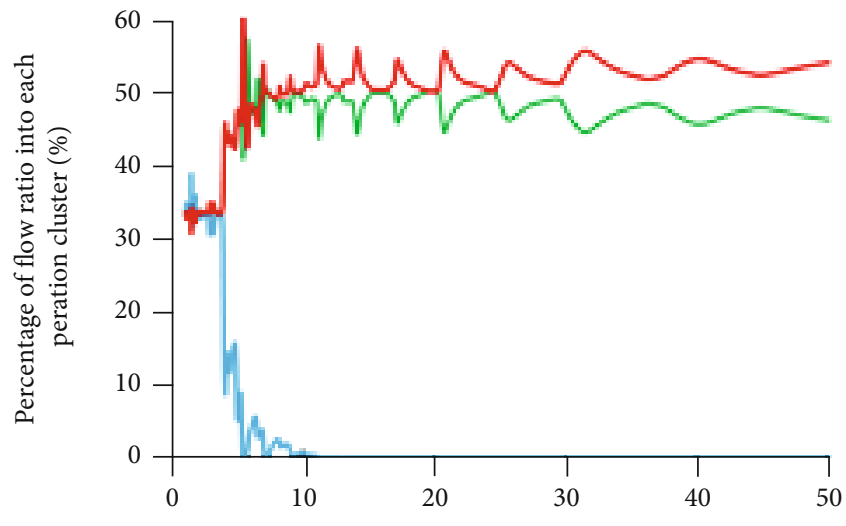

Injection time/s

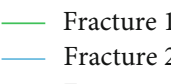

a)

(b)

Figure 8: Percentage of flow into each cluster as a function of time for different flow rates: (a) case $1\left(6 \mathrm{~m}^{3} / \mathrm{min}\right)$; (b) case $2\left(10 \mathrm{~m}^{3} / \mathrm{min}\right)$. 


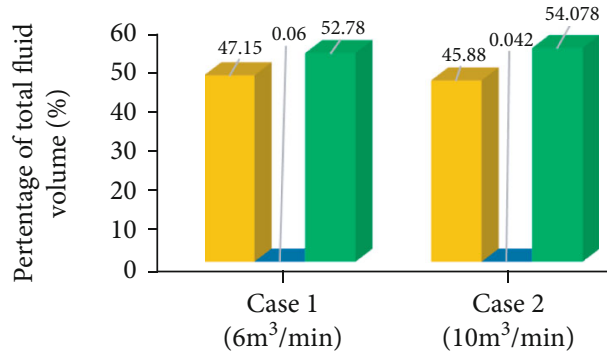

(a) $t=20 \mathrm{~s}$

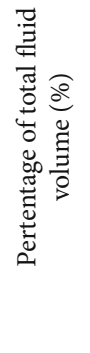

- Fracture 2

- Fracture 3

(b) $t=50 \mathrm{~s}$

Figure 9: The total fluid volume distribution of each cluster after pumping for $20 \mathrm{~s}$ and $50 \mathrm{~s}$ for two different flow rates.

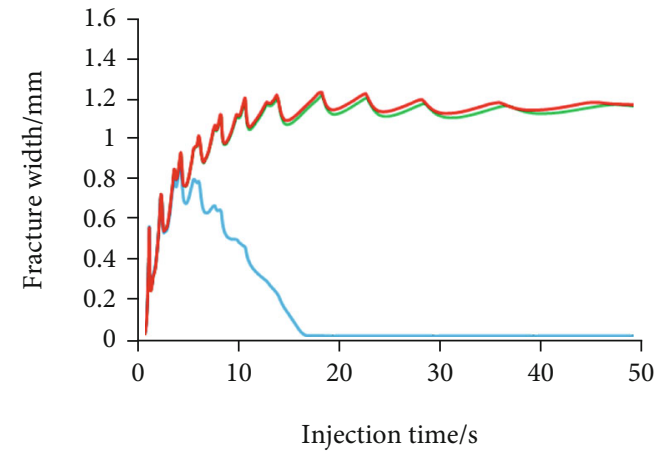

(a)

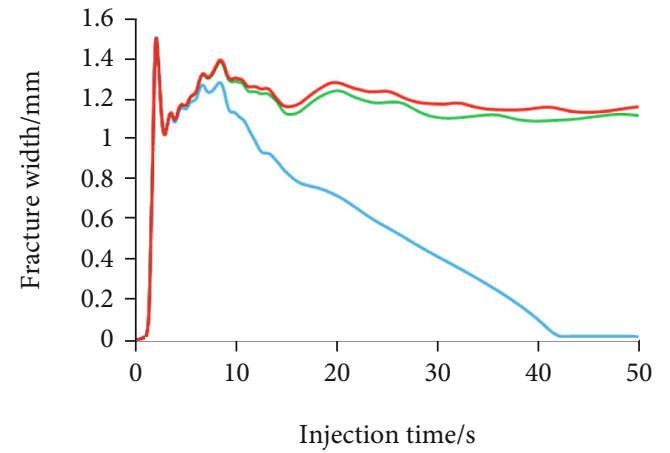

(b)

FIGURE 10: The maximum fracture width of each cluster as a function of time for different fracturing 484 fluid viscosities: (a) case 1 (1 cp); (b) case $3(100 \mathrm{cp})$.

viscosities are considered, namely, $1 \mathrm{cp}$ and $100 \mathrm{cp}$. The fracture geometry injected with fluid in case 1 is shown in Figure 5, and that injected with fluid in case 3 is shown in Figure 6.

A plot of the change in the maximum fracture width along the direction of fracture propagation is shown in Figure 10. As shown in Figure 10(a), the width of the fracture increases rapidly with the initiation of the fracture, and the width of the middle fracture decreases continuously until it approaches $0 \mathrm{~mm}$. The fractures on both sides continue to fluctuate and rise, and the widths of the three fractures remain stable after a period of fluid injection. The difference is that as shown in Figure 10(b), in case 3 (with higher fracturing fluid viscosity), the middle fracture propagates for a longer time, and the overall width of the three fractures is larger than that in case 1. According to Figure 10(a), the maximum fracture widths of fractures 1 , 2, and 3 are $1.2 \mathrm{~mm}, 0.895 \mathrm{~mm}$, and $1.23 \mathrm{~mm}$, respectively. The maximum width of fracture 2 is almost zero after $17 \mathrm{~s}$. According to Figure 10(b), the maximum fracture widths of fractures 1,2 , and 3 are $1.47 \mathrm{~mm}, 1.47 \mathrm{~mm}$, and $1.47 \mathrm{~mm}$, respectively. The maximum width of fracture 2 is almost zero after $42 \mathrm{~s}$. Combined with Figures 11 and 10, it can be seen that with the increase in fracturing fluid viscosity, the middle fracture continues to propagate after $20 \mathrm{~s}$ of pumping, but the area of its propagation is much smaller than that of fracture propagation on both sides. After pump- ing for $50 \mathrm{~s}$, the middle fracture is closed, the fractures on both sides continue to propagate, and the overall width of the fractures increases. Compared to fracture 1, fracture 3 is closer to the pumping point. As shown in Figure 11, when the viscosity increases from $1 \mathrm{cp}$ to $100 \mathrm{cp}$, the range of large fracture width of fracture 3 (represented as yellow and red area) is greater than that of fracture 1. It means that as the fracturing fluid viscosity increases, the flow friction becomes higher and the effect of wellbore friction becomes relatively more pronounced.

The dynamic percentage of the flow rate into each cluster is illustrated in Figure 12. In Figure 12(a), the percentage of flow into fracture 2 is almost 0 after $14 \mathrm{~s}$. The percentages of flow into fracture 1 and fracture 3 are almost identical. The percentages of flow into fracture 1 and fracture 3 are almost the same at first, but as more fracturing fluid is pumped, the flow percentage into fracture 1 is gradually higher than that entering fracture 3 , and this trend slowly increases. However, Figure 12(b) shows that the percentage of flow into fracture 2 is almost zero after $33 \mathrm{~s}$. The flow percentages into fracture 1 and fracture 3 rapidly diverge as the percentage of flow into fracture 2 decreases. Moreover, with the increase of injection time, the difference of the flow percentages into fracture 1 and fracture 3 becomes further greater. Combined with Figures 10 and 12, it can be seen that as the fracturing fluid is pumped, the three fractures initiate simultaneously and divide the injected fracturing fluid 

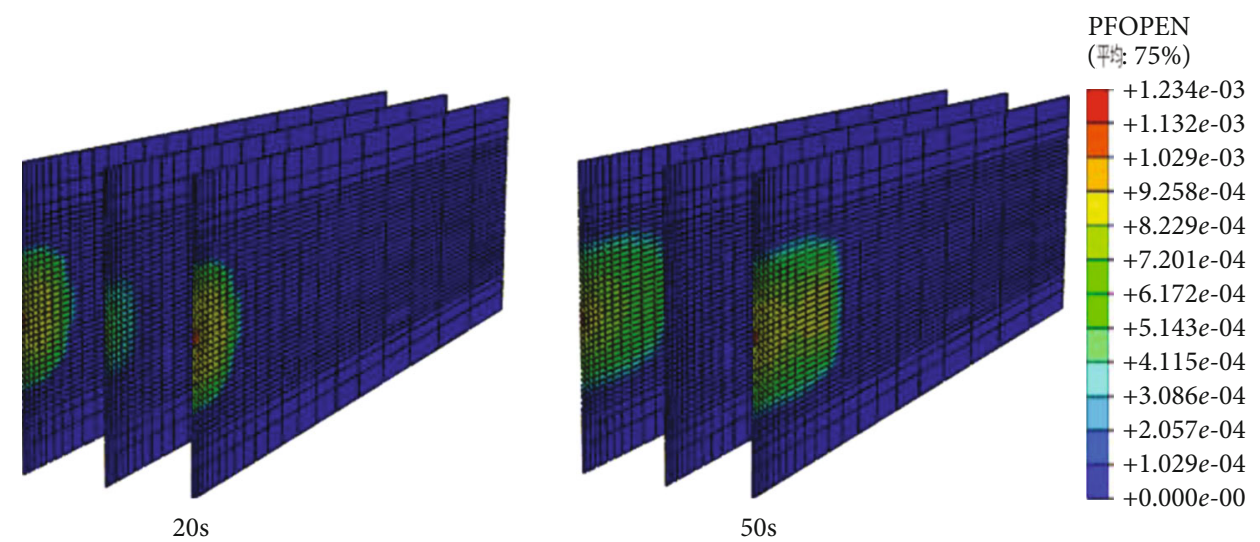

FIGURE 11: Fracture geometry after pumping for $20 \mathrm{~s}$ and $50 \mathrm{~s}$ in case 3.

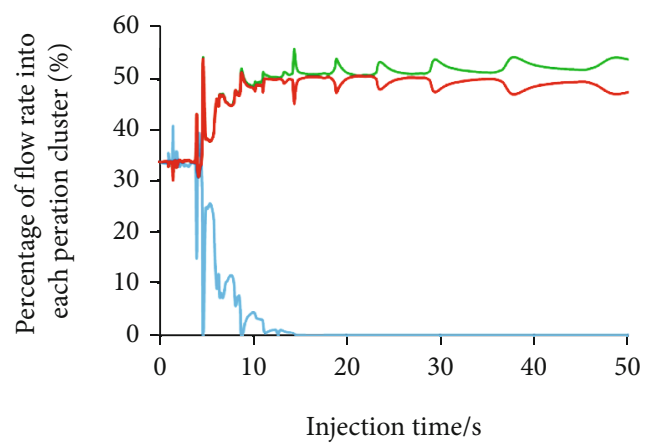

Injection time/s

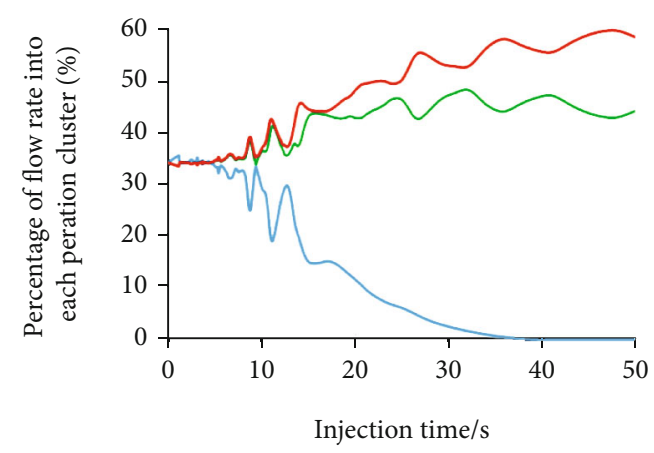

Fracture 1
- Fracture 2
- Fracture 3

(a)

(b)

Figure 12: Percentage of flow into each cluster as a function of time for different fracturing fluid viscosities: (a) case 1 (1 cp); (b) case 3 $(100 \mathrm{cp})$.

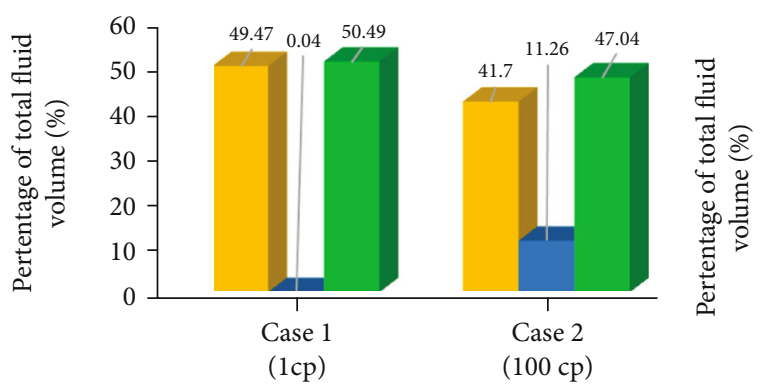

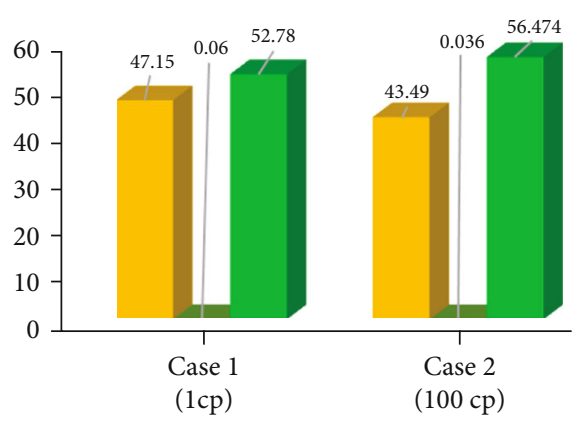

- Fracture 1

- Fracture 2

- Fracture 3

FIGURE 13: The total fluid volume distribution of each cluster after pumping for $20 \mathrm{~s}$ and $50 \mathrm{~s}$ for two different fracturing fluid viscosities.

equally. However, with the increase of pump injection time, the fracturing fluid of middle fracture gradually decreases. With the decrease of the middle fracture's fracturing fluid proportion, the difference of the fracturing fluid proportion of fractures on both sides gradually increased, suggesting that when fracturing fluid viscosity is bigger, it can reduce the effect of stress shadow to some extent and amplify the effect of wellbore friction.

After pumping for $20 \mathrm{~s}$ and $50 \mathrm{~s}$, the percentage of flow into each cluster is presented in Figure 13. The percentage 


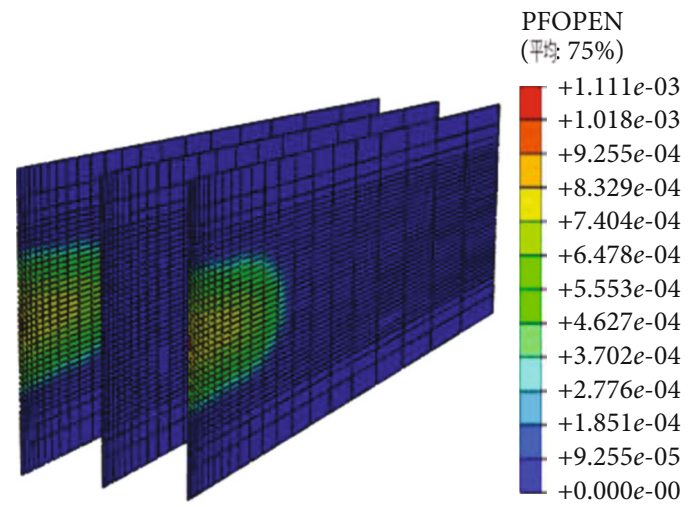

(a)

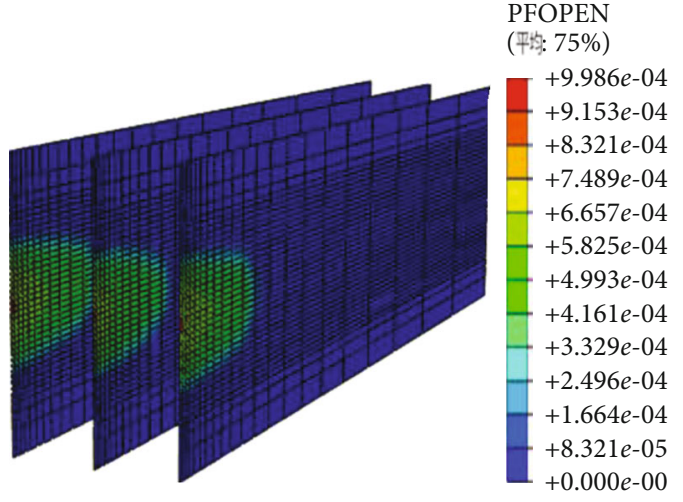

(b)

Figure 14: Fracture geometry after pumping for $50 \mathrm{~s}$ for different perforation frictions: (a) case 4; (b) case 5.

of flow into fracture 2 is minimal and is much smaller than the percentage of flow into the fractures on either side. The percentage of flow into fracture 3 is more than the percentage of flow into fracture 1 because of the effect of wellbore fluid friction. When the fracturing fluid viscosity ranges from $1 \mathrm{cp}$ to $100 \mathrm{cp}$, however, due to the stress shadow effect, fracture 2 still cannot be fully developed. However, after pumping for $20 \mathrm{~s}$, in case 2 , the percentage of the total fluid volume of the middle fracture is $11.26 \%$, which is much larger than that of the middle fracture in case 1, which is $0.04 \%$. After pumping for $50 \mathrm{~s}$, the flow rate uniformity into the two sides of the fracture worsens because of the higher fracturing fluid viscosity, from a $5.63 \%$ to $12.984 \%$ difference. Therefore, we believe that fracturing fluid viscosity is conducive to the uniform development of fractures when perforation friction is not considered and that increasing fracturing fluid viscosity can improve fracture width. However, when fracture 2 is no longer developed, the flow into fracture 2 cannot be evenly distributed between the other two fractures.

In engineering, when perforating friction is small, simply increasing the fracturing fluid viscosity can help multiple fractures develop to a certain extent. Unfortunately, the development of each fracture will be reduced to a certain extent.

6.4. The Effect of Perforation Friction (Case 1, Case 4, and Case 5). In this section, the influence of perforation friction is studied. In multicluster fracturing, a change in the number of perforations in each perforation cluster or perforation diameter directly leads to a change in perforation friction. Therefore, the effect of perforation friction on the simultaneous propagation of multiple fractures in multicluster fracturing is investigated in three cases: in addition to case 1 , one with eight perforations per cluster and a perforation diameter of $15 \mathrm{~mm}$ (case 4 ) and the second with 32 perforations per cluster and a perforation diameter of $5 \mathrm{~mm}$ (case 5). Equation (6) shows that with the change in the number of perforations or perforation diameter, the perforation friction changes, thus changing the initiation and propagation of multiple fractures. In this section, according to the perforation parameters set in different cases, the value of perfora- tion friction is case $5>$ case $4>$ case 1 . The fracture geometry injected with fluid in case 1 is shown in Figure 5, the fracture geometry injected with fluid in case 4 is shown in Figure 14(a), and that injected with fluid in case 5 is shown in Figure 14(b).

The change curve image of the maximum fracture width along the direction of fracture propagation is shown in Figure 15. As shown in Figures 1(a) and 15(b), with the initiation of the fractures, the width of the fractures increases rapidly, and the width of the middle fracture decreases continuously until it is close to $0 \mathrm{~mm}$. The fractures on both sides continued to fluctuate, and the widths of the three fractures remained stable after a period of fluid injection. The difference, as shown in Figure 15(c), is that in case 5 (with high perforation friction), the development continued after pumping for $50 \mathrm{~s}$, and the widths of the three fractures remained stable after a period of injection, with the widths of the middle fractures being slightly smaller than those of the sides when stable.

The dynamic percentage of the flow rate into each cluster is illustrated in Figure 16. Figure 16(a) shows that the percentage of flow into fracture 2 is almost 0 after $17 \mathrm{~s}$. The percentage of flow into fracture 1 and fracture 3 is almost identical. The percentage of flow into fracture 1 and fracture 3 is almost the same at first, but as more fracturing fluid is pumped, the flow percentage into fracture 1 is gradually higher than that entering fracture 3 , and this trend slowly increases. In Figure 16(b), the percentage of flow into fracture 2 is almost 0 after $28 \mathrm{~s}$. The percentage of flow into fracture 1 and fracture 3 is almost identical. However, as you can see from Figure 16(c), although the percentage of flow into fracture 2 is slightly smaller than that into the other two fractures, it still propagates until $50 \mathrm{~s}$. In combination with Figures 14 and 16, it can be seen that when the perforation friction increases by a certain amount, the fracture propagation has the same trend; that is, the three fractures begin to evenly divide the injected fracturing fluid and initiate. After a period of propagation, the middle fracture is closed, and the fractures on both sides continue to propagate.

However, in combination with Figures 14 and 17, it can be seen that when the perforation friction increases to a 


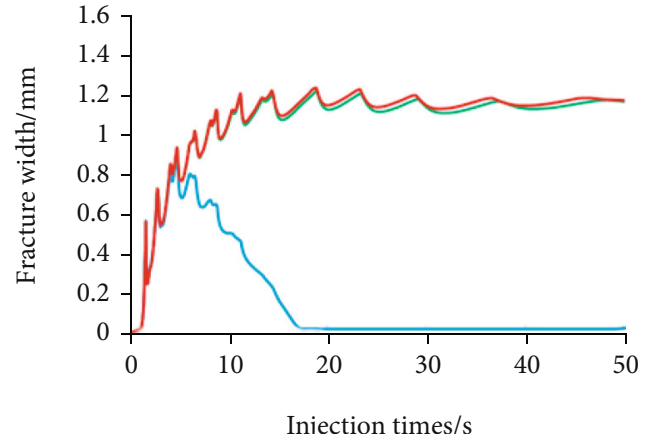

(a)

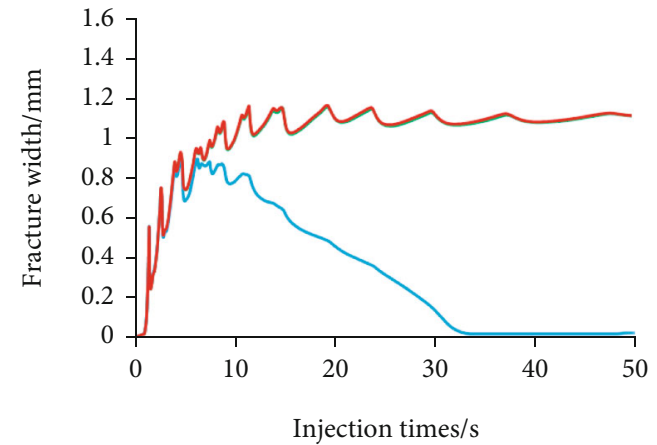

(b)

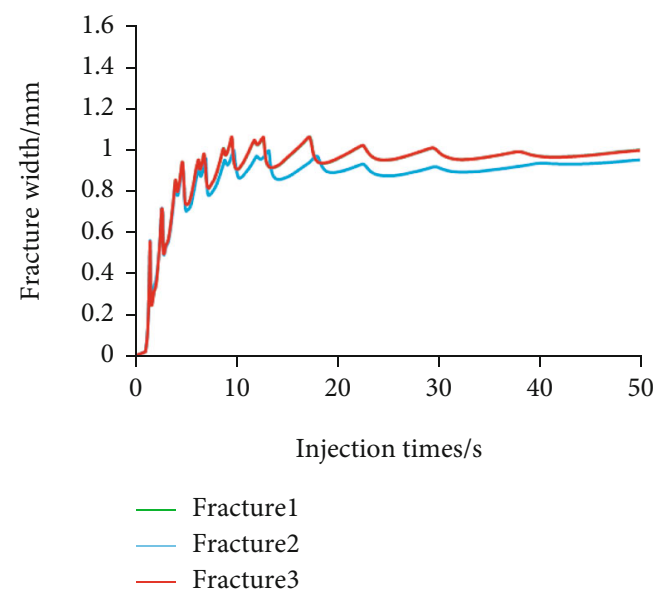

(c)

FIGURE 15: The maximum fracture width of each cluster as a function of time for different perforation design parameters: (a) case 1; (b) case 4 ; (c) case 5.

certain extent, the middle fracture does not close during pumping for $50 \mathrm{~s}$. The three fractures first divide fracturing fluid evenly and initiate and then propagate together. There is a small decrease in the proportion of fracturing fluid in the middle fracture.

After pumping for $20 \mathrm{~s}$ and $50 \mathrm{~s}$, the total fluid volume distribution of each cluster is presented in Figure 18. Case 1 and case 4 show that the percentage of flow into fracture 2 is the minimum and is much smaller than the percentage of flow into the fractures on either side due to the impact of stress shadow effect which causes the pressure of fracture 2 to be too large to allow fracturing fluid to enter. The percentage of flow into fracture 3 is more than the percentage of flow into fracture 1 due to the presence of wellbore friction. The difference between the percentage of flow into fracture 1 and fracture 2 was reduced from $5.63 \%$ to $0.69 \%$ $(t=50 \mathrm{~s})$ due to the change in perforation friction. The influence of perforating friction is much greater than that of wellbore friction. With the increase of perforation friction, the compressive stress field applied by the two sides of the fractures to the middle fracture will be improved, and the influence of stress shadow effect can be effectively suppressed. Therefore, in case 5, all three fractures are initiated and fully developed simultaneously, the percentage of flow into 2 is $5.53 \%$ lower than the percentage of flow into fracture 1 , the percentage of flow into fracture 1 and fracture 3 is nearly the same, and the percentage of flow into fracture 2 exhibits a small decrease.

The increase in perforation friction (e.g., the decrease in the number of perforations or the diameter of perforations) contributes to the uniform propagation of multiple fractures. However, with the increase in perforating friction, the bottomhole pressure increases greatly, and the pressure at the fracture mouth is not similar to the bottomhole pressure but far less than the bottomhole pressure. To quantitatively study the influence of perforation friction on the bottomhole pressure and pressure at the fracture mouth, the bottomhole pressure and pressure at the three fracture mouths are compared in Figure 17 when the fracturing continues for $50 \mathrm{~s}$. The bottomhole pressure is almost identical to the pressure at every fracture mouth when the perforating friction is not considered. However, when perforating friction is considered, the pressure at the fracture mouth and the bottomhole pressure increase. In case 4 , the pressure at the middle fracture mouth is close to the bottomhole pressure, while the pressure at the lateral fracture is small. In case 5, compared with the bottomhole pressure, the pressure at the fracture mouth of the three fractures decreases significantly, and the middle fracture $(50.4 \mathrm{MPa})$ is slightly higher than the two sides $(49.2 \mathrm{MPa})$. This is due to the greater perforation friction in case 5 and more equal distribution of fracturing fluid to the three fractures, all of which are affected by the 


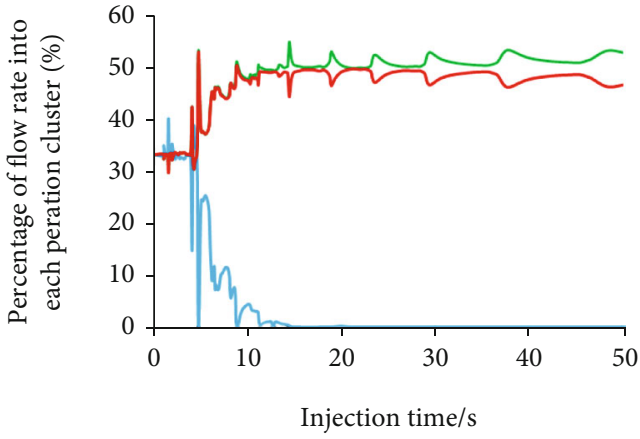

(a)

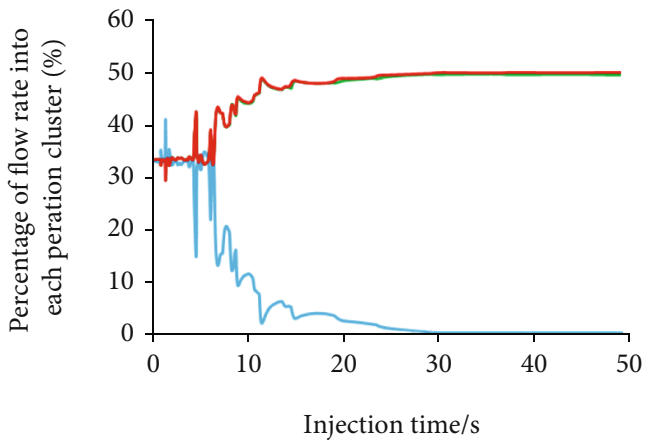

(b)

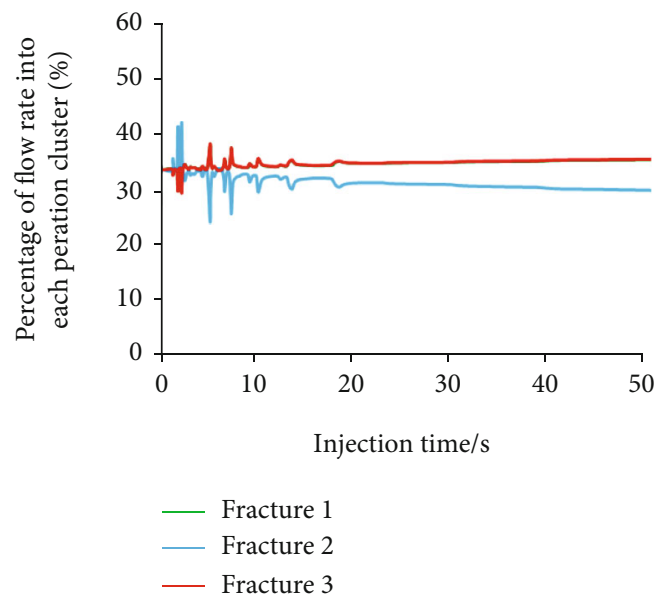

(c)

Figure 16: Percentage of flow into each cluster as a function of time for different perforation design parameters: (a) case 1; (b) case 4; (c) case 5.

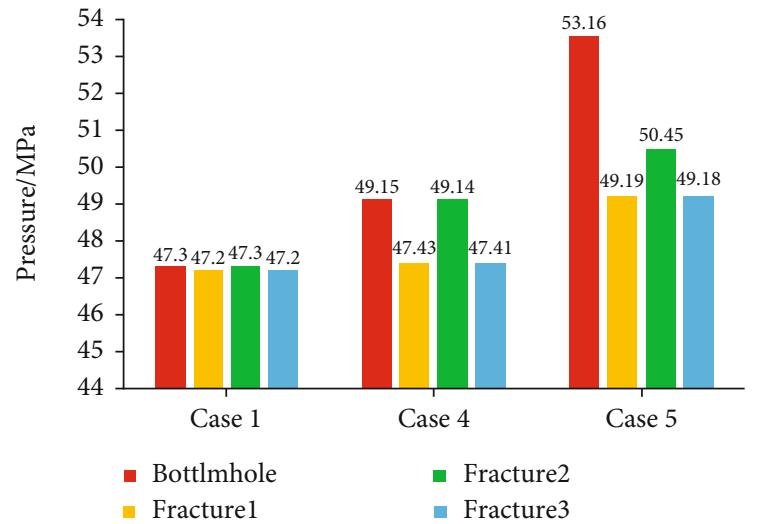

FiguRE 17: Bottomhole pressure and pressure at various fracture mouths when fracturing for $50 \mathrm{~s}$ for three different perforation design parameters.

perforation friction as they propagate. Through the analysis, it is believed that perforation friction can reduce the impact of stress shadows due to the uniform development of multiple fractures, but increasing perforation friction leads to an increase in the bottomhole pressure, so engineering equipment is more demanding.

In engineering, increasing perforation friction can effectively help multiple fractures develop. However, as the perfo- rating friction increases, higher engineering pressure is required for fracture propagation. Therefore, it is necessary to find an appropriate perforation design.

6.5. The Effect of the Injection Rate when the Value of Perforation Friction Is Large (Case 5, Case 6, and Case 7). In this section, the influence of the flow rate on multicluster fracturing is studied with the existence of perforation friction. Three flow rates are considered: $6 \mathrm{~m}^{3} / \mathrm{min}$ (case 5), $8 \mathrm{~m}^{3} / \mathrm{min}$ (case 6 ), and $10 \mathrm{~m}^{3} / \mathrm{min}$ (case 7 ).

The change curve image of the maximum fracture width along the direction of fracture propagation is shown in Figure 19. For different flow rates, the curves show similar characteristics. A higher flow rate leads to a larger fracture width. As a higher percentage of the fluid flows into the second fracture when the flow rate increases from $6 \mathrm{~m}^{3} / \mathrm{s}$ to $10 \mathrm{~m}^{3} / \mathrm{s}$ (see Figure 19), a high flow rate is more beneficial to the propagation of the middle fracture. For example, up to $50 \mathrm{~s}$, the maximum fracture widths of fractures 1,2 , and 3 are $1 \mathrm{~mm}, 0.95 \mathrm{~mm}$, and $1 \mathrm{~mm}$, respectively, and the maximum fracture width of the middle fracture is slightly smaller than the maximum fracture width of the fractures on both sides. In addition, as the injection rate increases, the maximum widths of the three fractures tend to be the same after injection for $50 \mathrm{~s}$. Combined with Figures 14, 19 , and 20 , it can be seen that as the flow rate increases, 


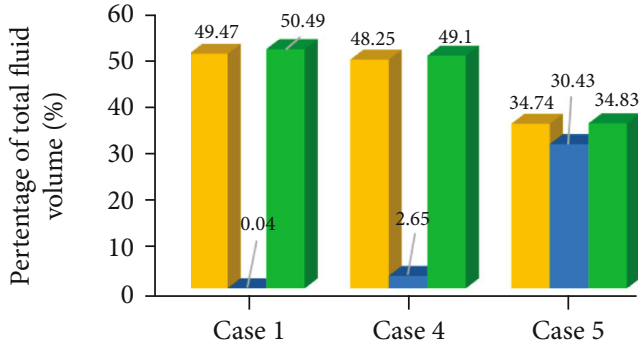

(a) $t=20 \mathrm{~s}$
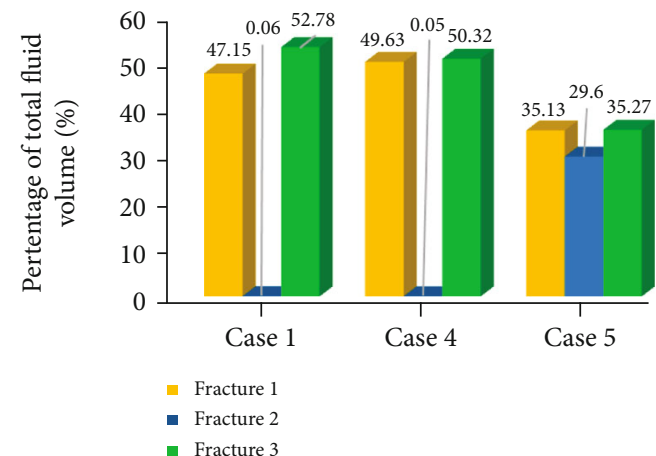

(b) $t=50 \mathrm{~s}$

FIgURE 18: The total fluid volume distribution of each cluster after pumping for $20 \mathrm{~s}$ and $50 \mathrm{~s}$ for three different perforation design parameters.

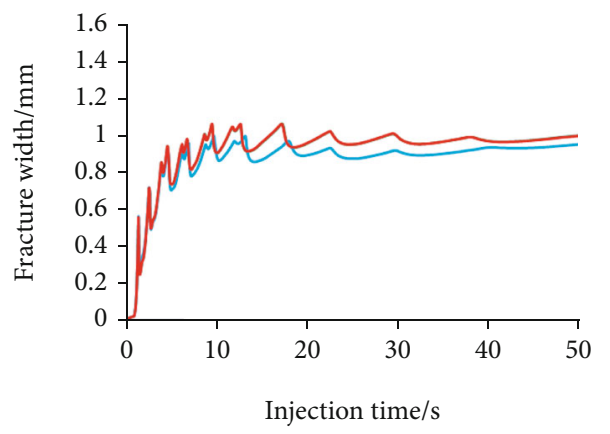

(a)

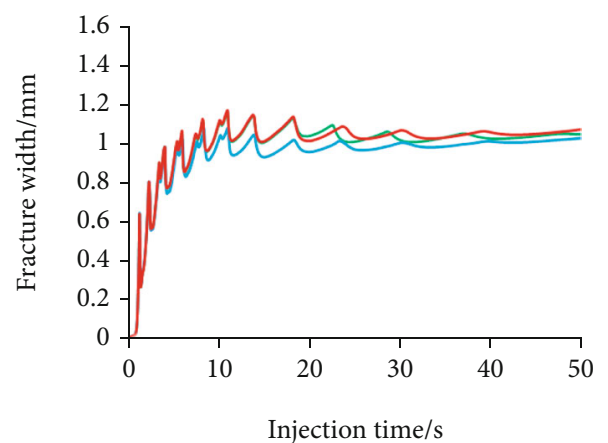

(b)

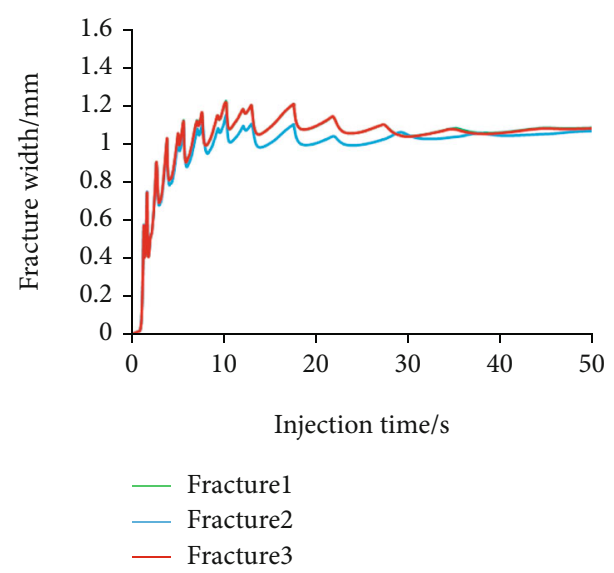

(c)

Figure 19: The maximum fracture width of each cluster as a function of time for different flow rates: (a) case 5 (6 $\left.\mathrm{m}^{3} / \mathrm{min}\right)$; (b) case 6 $\left(8 \mathrm{~m}^{3} / \mathrm{min}\right)$; (c) case $7\left(10 \mathrm{~m}^{3} / \mathrm{min}\right)$.

the three fractures have a similar tendency to propagate such that the three fractures initially divide the pumped fracturing fluid equally and initiate at the same time. As fracturing fluid is pumped in, three fractures continue to propagate. In addition, the fracture length increases with the injection rate.

When the fracturing time is $50 \mathrm{~s}$, the comparison of the bottomhole pressure and the fracture width pressure is shown in Figure 21. With increasing injection rate, the bottomhole pressure increases faster, but the pressure at the fracture mouth increases less, and the difference between the two increases. The difference between the bottomhole pressure and the pressure at the fracture mouth is most remarkable when the injection rate is $10 \mathrm{~m}^{3} / \mathrm{min}$. In each case, the pressure at the fracture mouth of the middle fracture is slightly greater than that at the two sides.

Because perforation friction weakens the stress shadow effect, the effect of the total flow rate on multicluster fracturing becomes evident and is conducive to the uniform 


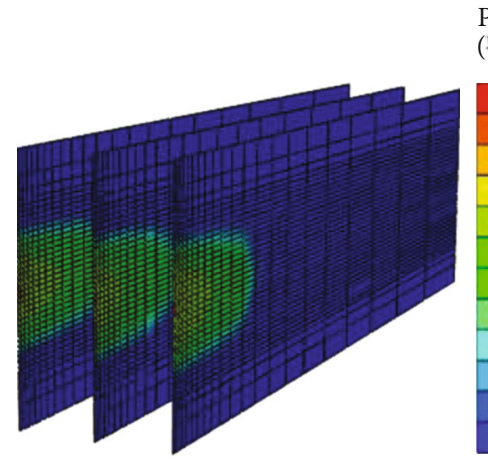

(a) $t=20 \mathrm{~s}$

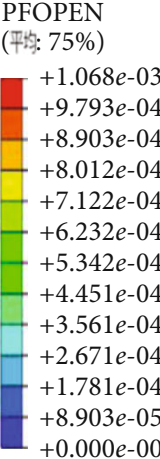

$+0.000 e-00$

Figure 20: Fracture geometry after pumping for $50 \mathrm{~s}$ for different injection rates: (a) case $6\left(8 \mathrm{~m}^{3} / \mathrm{min}\right)$; (b) case 7 (10 $\left.\mathrm{m}^{3} / \mathrm{min}\right)$.

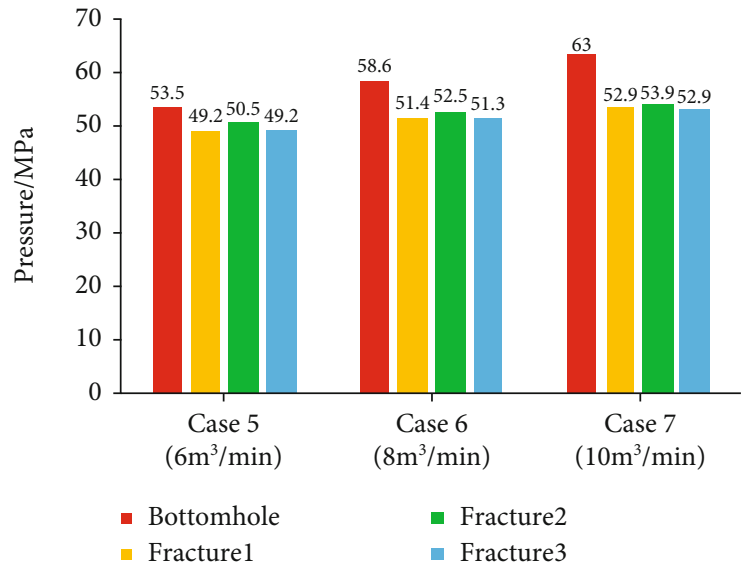

Figure 21: Bottomhole pressure and pressure at various fracture mouths when fracturing for $50 \mathrm{~s}$ for three different flow rates.

propagation of multiple fractures. As the flow rate increases, the bottomhole pressure gradually increases. At this time, the influence of the perforation friction will be enhanced, leading to a greater drop in bottomhole pressure at the fracture mouth and a greater difference between the pressure at fracture mouth and the bottomhole pressure. As the total flow rate increases, the fracture length of each fracture increases after pumping for $50 \mathrm{~s}$, but increasing the total flow rate also increases the engineering pressure and has little effect on the fracture width.

In engineering, when perforation friction is high, increasing the injection rate is favourable for multiple fracture propagation. However, as the injection rate increases, high engineering pressure is required for each fracture propagation, and higher requirements on the field equipment is also a challenge.

6.6. The Effect of Fracturing Fluid Viscosity when the Value of Perforation Friction Is Large (Case 5, Case 8, and Case 9). In this part, the influence of the flow rate on multicluster fracturing is considered based on perforation friction. Each cluster has 32 perforations, the perforation diameter is $5 \mathrm{~mm}$, the total flow rate is $6 \mathrm{~m}^{3} / \mathrm{min}$, and the fracture fluid viscosity is

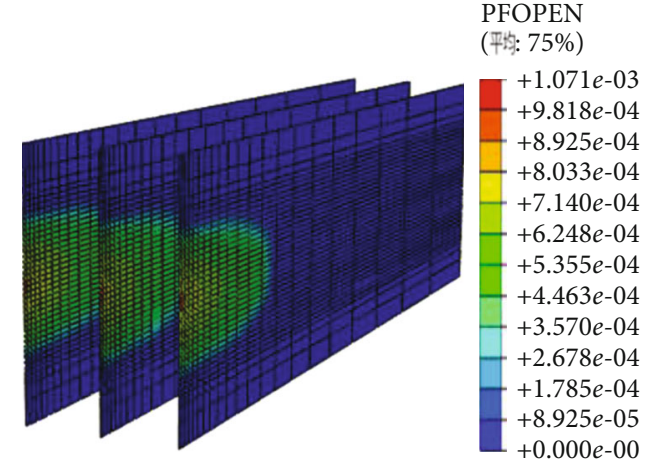

(b) $t=50 \mathrm{~s}$

set to $10 \mathrm{cp}$ and $100 \mathrm{cp}$. Based on the reference model in case 5, different fracturing fluid viscosities are considered, namely, $10 \mathrm{cp}$ and $100 \mathrm{cp}$. The fracture geometry injected with fluid in case 5 is shown in Figure 2, the fracture geometry injected with fluid in case 8 is shown in Figure 22(a), and that injected with fluid in case 9 is shown in Figure 22(b).

The change curve image of the maximum fracture width along the direction of fracture propagation is shown in Figure 23. As shown in Figures 23(a) and 23(b), with the initiation of fractures, the width of fractures increases rapidly, and the three fractures continue to fluctuate and remain stable after a period of fluid injection. In case 5 , the maximum fracture width of fracture 2 is slightly lower than fracture 1 and fracture 3 , while in case 8 , the maximum fracture width of three fractures is nearly equal. As shown in Figure 23(c), the difference is that in case 9 (higher fracturing fluid viscosity), the width of the three fractures increases sharply as the fracture is initiated and gradually decreases as the fracturing fluid is pumped in. After some time, the widths of the three fractures remain stable as the fluid is pumped in. According to Figures 23(a) and 23(b), the maximum fracture widths in both cases are almost the same, approximately $1.1 \mathrm{~mm}$. However, according to Figure 23(c), the maximum fracture widths of fracture 1,2 , and 3 are $1.506 \mathrm{~mm}, 1.506 \mathrm{~mm}$, and $1.506 \mathrm{~mm}$, respectively. Compared with the previous two cases, the maximum fracture widths increased by $0.4 \mathrm{~mm}$. As seen from Figure 23, with the increase of fracturing fluid viscosity, after injecting the $50 \mathrm{~s}$, the maximum widths of the three fractures tend to be the same when the fracturing fluid is $10 \mathrm{cp}$. When the fracturing fluid viscosity is $100 \mathrm{cp}$, the maximum widths of fractures 1,2 , and 3 are $1 \mathrm{~mm}$, $0.97 \mathrm{~mm}$, and $1 \mathrm{~mm}$, respectively. Combined with Figures 5, 22, and 23, it can be seen that as the flow rate increases, the three fractures have a similar tendency to propagate such that the three fractures initially divide the pumped fracturing fluid equally and initiate at the same time. As fracturing fluid is pumped in, three fractures continue to propagate. However, as the fracturing fluid viscosity increased, the fracture width increased, but the length and height of all three fractures decreased, especially the middle fracture. 


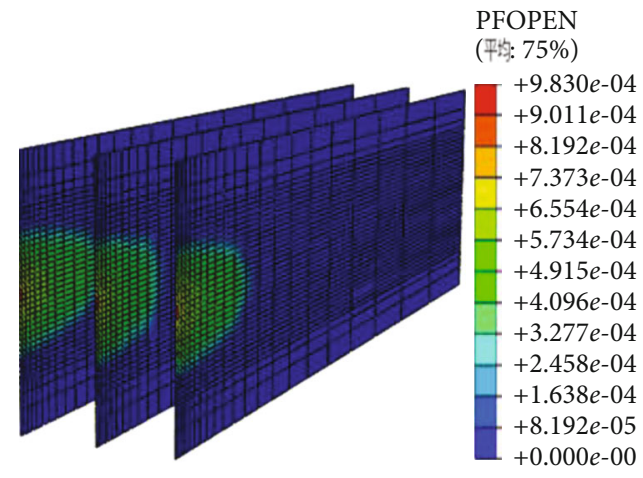

(a)

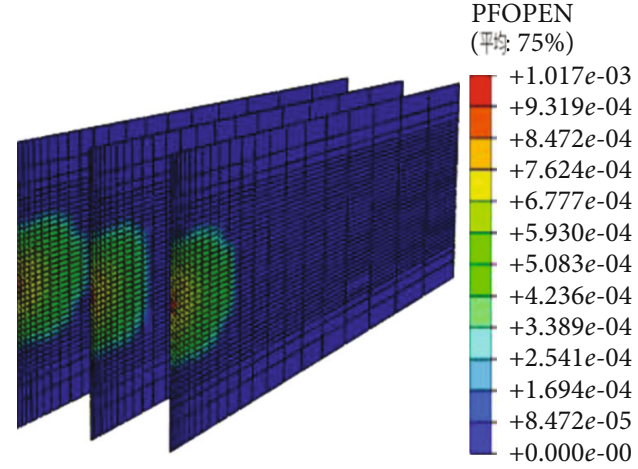

(b)

Figure 22: Fracture geometry after pumping for $50 \mathrm{~s}$ for different fracturing fluid viscosities: (a) case 8 (10 cp); (b) case 9 (100 cp).

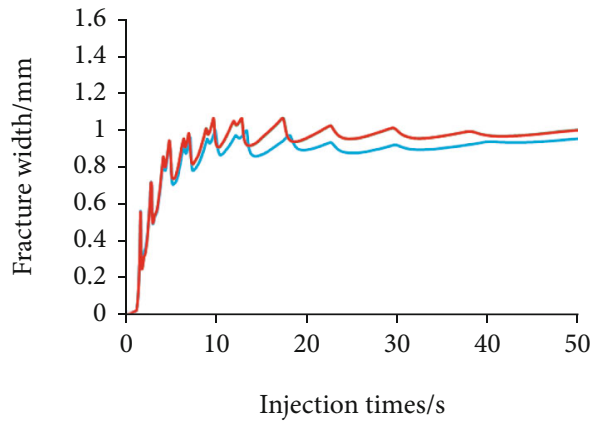

(a)

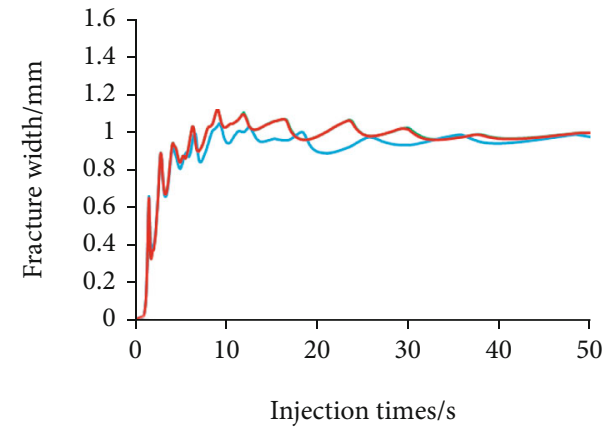

(b)

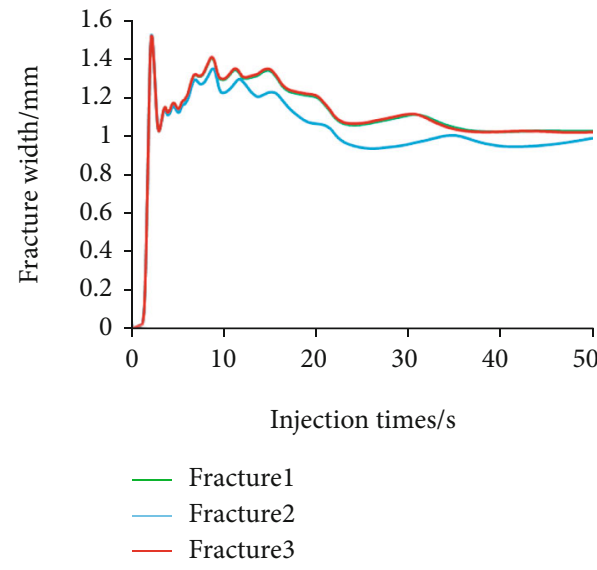

(c)

FIgURE 23: Maximum fracture width of each cluster as a function of time for different fracturing fluid viscosities: (a) case 5 (1 cp); (b) case 8 $(10 \mathrm{cp})$; (c) case 9 (100 cp).

When the fracturing time is $50 \mathrm{~s}$, the comparison of the bottomhole pressure and the fracture width pressure is shown in Figure 24. With the increase in fracturing fluid viscosity, the bottomhole pressure and the pressure at the fracture mouth show almost no change in the three kinds of cases. When fracturing fluid viscosity increases, higher fluid pressure in the fractures leads to greater fracture width. However, the bottomhole pressure and the pressure at the fracture mouth have no obvious change. It suggests that for engineering pressure, the effect of the injection rate is more obvious. With regard to the fracturing fluid viscosity, only the morphology of fracture is affected. There is no significant effect on the bottomhole pressure and the pressure at the fracture mouth.

As perforation friction weakens the stress shadow effect, the effect of fracturing fluid viscosity on multicluster fracturing is mainly reflected in the increase in fracture width and the decrease in fracture length and fracture height, and the effect on the uniform propagation of multiple fractures is not as obvious as when the stress shadow effect plays a dominant role. 


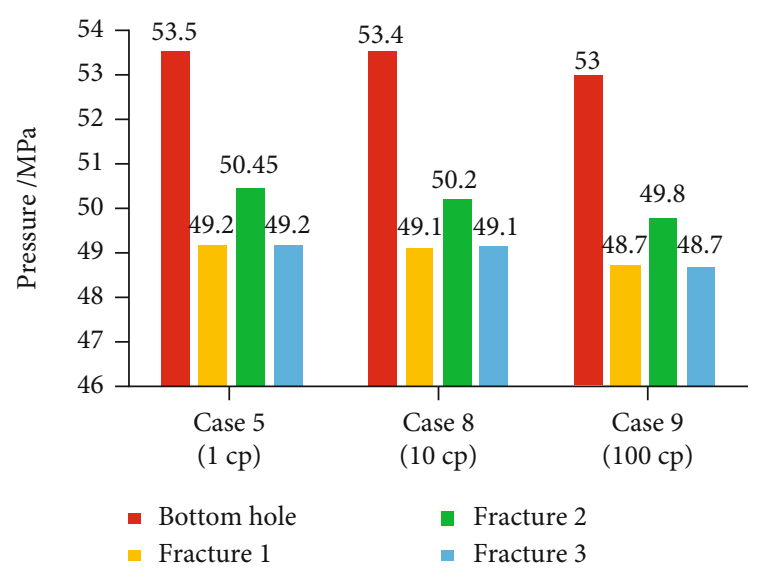

FIGURE 24: Bottomhole pressure and pressure at various fracture mouths when fracturing for $50 \mathrm{~s}$ for three different fracturing fluid viscosities.

In engineering, when the perforating friction is large, to the effect of high viscosity on the uniform development of multiple fractures can be ignored.

\section{Conclusions}

In this study, based on the CZM model and Bernoulli equation, we established a three-dimensional multicluster fracturing model with multiple clusters of fractures simultaneously initiating and propagating considering perforation friction and explored how engineering parameters affect the uniform development of multiple fractures through this model. Some key conclusions are as follows:

(1) Increasing perforation friction by reducing the number of perforations in each perforation cluster or the diameter of perforation can effectively reduce the influence of the stress shadow effect and make the development of each fracture more uniform

(2) Increasing the viscosity of the fracturing fluid under the influence of stress shadows can increase the fracture width and effectively improve the problem that middle cluster fractures cannot develop

(3) When the stress shadow effect is weakened by perforating friction and dynamic partitioning of the flow rate is dominant, increasing the injection rate can promote the development of multiple fractures more evenly. In this case, the fracturing fluid viscosity has little effect on the uniform development of fractures and can only increase the width of fractures to a certain extent

(4) To promote the uniform development of multiple fractures by increasing perforation friction and the injection rate increase in the engineering pressure, it is necessary to comprehensively consider the setting of engineering parameters according to the actual engineering capacity

\section{Data Availability}

The chart data used to support the findings of this study are included within the article.

\section{Conflicts of Interest}

The authors declare that there are no conflicts of interest regarding the publication of this paper.

\section{References}

[1] Q. Zhang, X.-P. Zhang, and W. Sun, "A review of laboratory studies and theoretical analysis for the interaction mode between induced hydraulic fractures and pre-existing fractures," Journal of Natural Gas Science and Engineering, vol. 86, p. 103719, 2021.

[2] K. H. S. M. Sampath, M. S. A. Perera, and P. G. Ranjith, “Theoretical overview of hydraulic fracturing break-down pressure," Journal of Natural Gas Science and Engineering, vol. 58, pp. 251-265, 2018.

[3] N. P. Roussel, "Implications of fracturing pressure data recorded during a horizontal completion on stage spacing design," in Society of Petroleum Engineers-SPE Hydraulic Fracturing Technology Conference, pp. 794-807, 2012,.

[4] A. P. P. Bunger, R. G. G. Jeffrey, and X. Zhang, "Constraints on simultaneous growth of hydraulic fractures from multiple perforation clusters in horizontal wells," SPE Journal (Society of Petroleum Engineers (U.S.) : 1996), vol. 19, no. 4, pp. 608620, 2014.

[5] X. L. Wang, C. Liu, H. Wang, H. Liu, and H. A. Wu, "Comparison of consecutive and alternate hydraulic fracturing in horizontal wells using XFEM-based cohesive zone method," Journal of Petroleum Science \& Engineering, vol. 143, pp. 14$25,2016$.

[6] H. Y. Wang, "Numerical investigation of fracture spacing and sequencing effects on multiple hydraulic fracture interference and coalescence in brittle and ductile reservoir rocks," Engineering Fracture Mechanics, vol. 157, pp. 107-124, 2016.

[7] B. Wang, F. Zhou, Y. Zou et al., "Effects of previously created fracture on the initiation and growth of subsequent fracture during TPMSF," Engineering Fracture Mechanics, vol. 200, pp. 312-326, 2018.

[8] J. Zhu, "Cluster spacing and well spacing optimization using multi-well simulation for the Lower Spraberry Shale in Midland Basin," in Society of Petroleum Engineers - SPE Liquids Rich Basins Conference - North America 2017, 2017.

[9] C. Miller, "Evaluation of production log data from horizontal wells drilled in organic shales," in Society of Petroleum Engineers-SPE Americas Unconventional Gas Conference 2011, pp. 623-645, UGC 2011, 2011.

[10] D. R. Spain, "Geo-engineered completion optimization: an integrated, multi-disciplinary approach to improve stimulation efficiency in unconventional shale reservoirs," in Society of Petroleum Engineers-SPE Middle East Unconventional Resources Conference and Exhibition 2015- The Journey of Unconventional Resources: From Exploration to Successful Development, pp. 88-99, 2015.

[11] W. El Rabaa, "Experimental study of hydraulic fracture geometry initiated from horizontal wells," SPE Reprint Series, vol. 47, pp. 166-173, 1998. 
[12] H. Zhu, J. Deng, X. Jin, L. Hu, and B. Luo, "Hydraulic fracture initiation and propagation from wellbore with oriented perforation," Rock Mechanics and Rock Engineering, vol. 48, no. 2, pp. 585-601, 2015.

[13] Y. Feng and K. E. Gray, "Parameters controlling pressure and fracture behaviors in field injectivity tests: a numerical investigation using coupled flow and geomechanics model," Computers and Geotechnics, vol. 87, pp. 49-61, 2017.

[14] J. E. Olson, Multi-Fracture Propagation Modeling: Applications to Hydraulic Fracturing in Shales and Tight Gas Sands, 42nd U.S. Rock Mechanics -2nd U.S.-Canada Rock Mechanics Symposium, 2008.

[15] Y. Cheng, "Impacts of the number of perforation clusters and cluster spacing on production performance of horizontal shale-gas wells," SPE Reservoir Evaluation \& Engineering, vol. 15, no. 1, pp. 31-40, 2012.

[16] S. Salimzadeh, T. Usui, A. Paluszny, and R. W. Zimmerman, "Finite element simulations of interactions between multiple hydraulic fractures in a poroelastic rock," International Journal of Rock Mechanics and Mining Sciences (Oxford, England: 1997), vol. 99, pp. 9-20, 2017.

[17] D. H. Shin and M. M. Sharma, "Factors controlling the simultaneous propagation of multiple competing fractures in a horizontal well," in Society of Petroleum Engineers-SPE Hydraulic Fracturing Technology Conference 2014, pp. 269-288, 2014.

[18] M. Haddad and K. Sepehrnoori, "XFEM-based CZM for the simulation of 3D multiple-cluster hydraulic fracturing in quasi-brittle shale formations," Rock Mechanics and Rock Engineering, vol. 49, no. 12, pp. 4731-4748, 2016.

[19] P. Zhao, L. Xie, Q. Ge, Y. Zhang, J. Liu, and B. He, "Numerical study of the effect of natural fractures on shale hydraulic fracturing based on the continuum approach," Journal of Petroleum Science \& Engineering, vol. 189, p. 107038, 2020.

[20] K. Wu, J. Olson, M. T. Balhoff, and W. Yu, "Numerical analysis for promoting uniform development of simultaneous multiple-fracture propagation in horizontal wells," SPE Production \& Operations, vol. 32, no. 1, pp. 41-50, 2017.

[21] K. Wu and J. E. Olson, "Mechanisms of simultaneous hydraulic-fracture propagation from multiple perforation clusters in horizontal wells," SPE Journal (Society of Petroleum Engineers (U.S.) : 1996), vol. 21, no. 3, pp. 1000-1008, 2016.

[22] J. Guo, Q. Lu, H. Zhu, Y. Wang, and L. Ma, "Perforating cluster space optimization method of horizontal well multi-stage fracturing in extremely thick unconventional gas reservoir," Journal of Natural Gas Science and Engineering, vol. 26, pp. 16481662, 2015.

[23] Z.-Z. Yang, L.-P. Yi, X.-G. Li, and W. He, "Pseudo-threedimensional numerical model and investigation of multicluster fracturing within a stage in a horizontal well," Journal of Petroleum Science \& Engineering, vol. 162, pp. 190-213, 2018.

[24] Q. Wang, Y. Hu, J. Zhao, S. Chen, C. Fu, and C. Zhao, "Numerical simulation of fracture initiation, propagation and fracture complexity in the presence of multiple perforations," Journal of Natural Gas Science and Engineering, vol. 83, p. 103486, 2020.

[25] J. Zhao, X. Chen, Y. Li, B. Fu, and W. Xu, "Numerical simulation of multi-stage fracturing and optimization of perforation in a horizontal well," Petroleum Exploration and Development, vol. 44, no. 1, pp. 119-126, 2017.
[26] D. Chuprakov, O. Melchaeva, and R. Prioul, "Injection-sensitive mechanics of hydraulic fracture interaction with discontinuities," Rock Mechanics and Rock Engineering, vol. 47, no. 5, pp. 1625-1640, 2014.

[27] W. Xu, J. Zhao, S. S. Rahman, Y. Li, and Y. Yuan, "A comprehensive model of a hydraulic fracture interacting with a natural fracture: analytical and numerical solution," Rock Mechanics and Rock Engineering, vol. 52, no. 4, pp. 1095$1113,2019$.

[28] E. Eberhardt, D. Stead, B. Stimpson, and E. Z. Lajtai, "The effect of neighbouring cracks on elliptical crack initiation and propagation in uniaxial and triaxial stress fields," Engineering Fracture Mechanics, vol. 59, no. 2, pp. 103-115, 1998.

[29] A. P. P. Bunger, X. Zhang, and R. G. G. Jeffrey, "Parameters affecting the interaction among closely spaced hydraulic fractures," SPE Journal (Society of Petroleum Engineers (U.S.) : 1996), vol. 17, no. 1, pp. 292-306, 2012.

[30] Y. Cheng, "Boundary element analysis of the stress distribution around multiple fractures: implications for the spacing of perforation clusters of hydraulically fractured horizontal wells," SPE Eastern Regional Meeting, pp. 267-281, 2009.

[31] B. Wheaton, "Integration of distributed temperature and distributed acoustic survey results with hydraulic fracture modeling: a case study in the Woodford shale," in Society of Petroleum Engineers - SPE/AAPG/SEG Unconventional Resources Technology Conference, 2016.

[32] B. Lecampion and J. Desroches, "Simultaneous initiation and growth of multiple radial hydraulic fractures from a horizontal wellbore," Journal of the Mechanics and Physics of Solids, vol. 82, pp. 235-258, 2015.

[33] A. P. Peirce and A. P. Bunger, "Interference fracturing: nonuniform distributions of perforation clusters that promote simultaneous growth of multiple hydraulic fractures," SPE Journal (Society of Petroleum Engineers (U.S.) : 1996), vol. 20, no. 2, pp. 384-395, 2015.

[34] X.-G. Li, L.-P. Yi, and Z.-Z. Yang, "Numerical model and investigation of simultaneous multiple-fracture propagation within a stage in horizontal well," Environmental Earth Sciences, vol. 76, no. 7, 2017.

[35] Y. Li, J. G. Deng, W. Liu, and Y. Feng, "Modeling hydraulic fracture propagation using cohesive zone model equipped with frictional contact capability," Computers and Geotechnics, vol. 91, pp. 58-70, 2017.

[36] J. B. Crump, "Effects of perforation-entry friction on bottomhole treating analysis," Journal of Petroleum Technology, vol. 40, no. 8, pp. 1041-1048, 1988.

[37] N. Modeland, "Statistical analysis of the effect of completion methodology on production in the Haynesville shale," in Society of Petroleum Engineers-SPE Americas Unconventional Gas Conference 2011, pp. 447-461, UGC 2011, 2011.

[38] C. G. Dávila, "Mixed-mode decohesion elements for analyses of progressive delamination," in Collection of Technical Papers-AIAA/ASME/ASCE/AHS/ASC Structures, Structural Dynamics and Materials Conference, vol. 3, pp. 2277-2288, 2001.

[39] M. L. Benzeggagh and M. Kenane, "Measurement of mixedmode delamination fracture toughness of unidirectional glass/epoxy composites with mixed-mode bending apparatus," Composites Science and Technology, vol. 56, no. 4, pp. 439449, 1996. 